\title{
An Interactive Chemical Dynamical Radiative Two-Dimensional Model of the Middle Atmosphere
}

\author{
G. Brasseur, ${ }^{1}$ M. H. Hitchman, ${ }^{2}$ S. Walters, ${ }^{1}$ M. Dymek, ${ }^{3}$ E. Falise ${ }^{3}$ and M. Pirre ${ }^{4}$
}

\begin{abstract}
This paper describes a new two-dimensional model of the stratosphere and the mesosphere in which dynamics, radiation and chemistry are treated interactively. The transport equations are expressed in the transformed Eulerian framework. Momentum deposition associated with Rossby wave absorption and gravity wave breaking and related eddy diffusion coefficients are parameterized as a function of the mean zonal state of the atmosphere. Diabatic heating and cooling is derived from the detailed National Center for Atmospheric Research community climate model radiative code. The distributions of chemically active species belonging to the oxygen, hydrogen, nitrogen and chlorine families are calculated for present-day conditions. By applying near the tropopause a different dynamical forcing in each hemisphere, the model produces significant hemispheric asymmetries in dynamical quantities (e.g., temperature) and trace gas densities (e.g., column ozone), in good agreement with climatological values. It is shown that the calculated distributions of source gases, such as nitrous oxide and methane, are very sensitive to the calculated (and parameterized) dynamical quantities and that species produced in the atmosphere, like carbon monoxide and odd nitrogen, can provide interesting information on the role of atmospheric transport. A major problem that remains to be elucidated is the underestimation by most models of the ozone density in the upper stratosphere. Because of the many feedback mechanisms included in its formulation, the model is well adapted to study the effects of human or natural perturbations. The response of the atmosphere to perturbations resulting from increasing emissions of $\mathrm{CO}_{2}$ and chlorofluorocarbons is considered.
\end{abstract}

\section{Introduction}

Two-dimensional chemical transport models have been extensively developed in the last 2 decades to study the behavior, as a function of latitude and height, of atmospheric trace species. These models provide useful information on the zonally averaged distribution and the sources and sinks as well as the meridional transport of these chemically active constituents. One advantage of two-dimensional formulations over one-dimensional models is their ability to represent the effects of dynamics in redistributing constituents in the meridional plane. A difficult problem, however, in representing zonally averaged distributions arises from the nature of stratospheric transport, which is due in large part to planetary waves and is thus three-dimensional by essence. In the so-called Eulerian models, the mass and energy fluxes are separated into a component involving the zonally averaged meridional winds and a component associated with the eddies, i.e., the departure of the variables from their zonal mean. The contribution by the eddies requires additional information through a closure relation by which the eddy transport of quasi-conservative tracer is specified in terms of the gradient of their mixing ratios (based on linear theory assumptions). In the two-dimensional models of the first generation, the mean circulation is prescribed, and the mixing coefficients are specified and are based on a mixing length hypothesis; their values are generally obtained from studies on the dispersion of nuclear debris

\footnotetext{
${ }^{1}$ National Center for Atmospheric Research, Boulder, Colorado.

${ }^{2}$ Department of Meteorology, University of Wisconsin, Madison.

${ }^{3}$ Belgian Institute for Space Aeronomy, Brussels.

${ }^{4}$ Laboratoire de Physique et Chimie de l'Environnement, Orléans, France.
}

Copyright 1990 by the American Geophysical Union.

Paper number 89JD02868.

0148-0227/90/89JD-02868\$05.00
[Reed and German, 1965; Gudiksen et al., 1968]. According to the noninteraction and nontransport theorems (see, for example, Andrews et al., [1987] for a discussion), however, the transport by the Eulerian mean circulation and by the large-scale eddies nearly cancel, so that inaccuracies in the specified diffusivities lead to significant errors in the determination of the net transport.

The assumption that eddy transport can be properly modeled by a simple diffusion law was questioned, for example, by Mahlman [1975], who found from a general circulation model (GCM) study that the eddy flux is not always diffusive in nature and that some of the assumptions made by Reed and German [1965] regarding the conservative nature of the species, the particle trajectory and the mean slope of the mixing surfaces are dubious. Solving the eddy perturbation equations with the linear wave approximation, it was found (see, for example, Plumb [1979], Pyle and Rogers [1980b], Matsuno [1980]) that the flux-gradient relation suggested by Reed and German can be retained but that the eddy tensor can be separated into a symmetric and an antisymmetric component. The latter, advective in character, depends on the mean parcel displacement and, if combined with the mean meridional circulation, provides an effective transport circulation. The former, which is a dispersive component, is determined by the time variation of the parcel displacement (transient eddies) and by the photochemical relaxation rate (chemical eddies). Dunkerton [1978] suggested that the transformed Eulerian mean (TEM) circulation (residual circulation) $\left(\bar{v}^{*}, \vec{w}^{*}\right)$ defined by Andrews and McIntyre [1976] and Boyd [1976]

$$
\begin{aligned}
\bar{v}^{*} & =\bar{v}-\frac{1}{\rho_{o}} \frac{\partial}{\partial z}\left[\frac{\rho_{o} \overline{v^{\prime} \theta^{\prime}} \cos \phi}{\partial \bar{\theta} / \partial z}\right] \\
\bar{w}^{*} & =\bar{w}+\frac{1}{a \cos \phi} \frac{\partial}{\partial \phi}\left[\frac{\overline{v^{\prime} \theta^{\prime}} \cos \phi}{\partial \bar{\theta} / \partial z}\right]
\end{aligned}
$$


where $(\bar{v}, \bar{w})$ represents the Eulerian mean (EM) circulation (see the notation section for other definitions) would account for essentially all the mass and energy transport and be similar to the diabatic circulation proposed earlier by Brewer [1949], Dobson [1956], and Murgatroyd and Singleton [1961] and to the Lagrangian mean circulation of air parcels. In the two-dimensional models developed following the TEM theory, based on a global advective transport circulation [e.g., Garcia and Solomon, 1983; Guthrie et al., 1984; Stordal, 1985], eddy diffusivities were nevertheless added in the thermodynamic and trace species continuity equations to account for transient and dissipative processes which are expected to become important especially in winter. The magnitude of the eddy diffusivities required by these models is approximately an order of magnitude smaller than in the classical Eulerian models. In this formulation, the values of the eddy diffusivity are usually specified empirically, and the relationships among dissipation mechanisms, the distribution of wave absorption, and irreversible mixing are therefore ignored. In the most recent models however, these processes are determined in a consistent manner.

The purpose of this paper is to describe a twodimensional model formulated in transformed Eulerian coordinates, in which chemical, radiative, and dynamical processes are treated interactively, and to present results obtained regarding the present-day and the perturbed atmosphere. The model includes a detailed radiative scheme which derives the diabatic heating rates consistently with calculated distributions of temperature and trace species densities. Calculated wave driving and eddy mixing coefficients resulting from gravity and Rossby wave absorption vary with the evolving distribution of the mean zonal wind. Through the large number of interactive processes included, the model is particularly adapted to the study of feedback mechanisms regulating the middle atmosphere when natural or man-made perturbations are produced.

\section{Model Description}

\subsection{Dynamics}

The model, which is used in the present study, extends from pole to pole with a latitudinal resolution of $5^{\circ}$ and from the surface to $85 \mathrm{~km}$ with a vertical resolution of $1 \mathrm{~km}$. The potential temperature and the chemical species are advected by the transformed Eulerian mean meridional circulation in log-pressure coordinates, which is forced by spatial gradients in wave driving and the related net radiative heating. The dynamical fields $\left(\bar{u}, \bar{v}^{*}, \bar{w}^{*}, \theta\right)$ are obtained from the thermodynanic, zonal momentum, mass continuity and thermal wind equations

$$
\begin{gathered}
\frac{\partial \bar{\theta}}{\partial t}+\bar{v}^{*} \frac{\partial \bar{\theta}}{\partial y}+\bar{w}^{*} \frac{\partial \bar{\theta}}{\partial z}=\bar{Q}+D_{\theta} \\
\frac{\partial \bar{u}}{\partial t}-\eta \bar{v}^{*}+\frac{\partial \bar{u}}{\partial z} \bar{w}^{*}=F \\
\frac{1}{\cos \phi} \frac{\partial}{\partial y}\left(\bar{v}^{*} \cos \phi\right)+\frac{1}{\rho_{o}} \frac{\partial}{\partial z}\left(\rho_{o} \bar{w}^{*}\right)=0 \\
\gamma \frac{\partial \bar{u}}{\partial z}=-\frac{g}{\theta} \frac{\partial \bar{\theta}}{\partial y}
\end{gathered}
$$

where

$$
\eta=f-\frac{1}{\cos \phi} \frac{\partial}{\partial y}(\bar{u} \cos \phi)
$$

is the absolute vorticity and where

$$
\gamma=f+2 \bar{u} \frac{\tan \phi}{a}
$$

The other variables are defined in the notation section. The eddy heat flux divergence $D_{\theta}$ expressed by

$$
D_{\theta}=-\frac{1}{\rho_{o}} \frac{\partial}{\partial z}\left[\rho_{o}\left(\overline{w^{\prime} \theta^{\prime}}+\frac{\partial \bar{\theta} / \partial y}{\partial \bar{\theta} / \partial z} \overline{v^{\prime} \theta^{\prime}}\right)\right]
$$

is generally small except where transience and dissipation is important, for example, in the mesosphere, where gravity wave breaking can cause a substantial downward heat flux. The wave driving $F$ is assumed to be due to Rossby $\left(F_{R}\right)$ and gravity $\left(F_{g}\right)$ wave dissipation, which can be expressed by the divergence of wave activity flux (or Eliassen-Palm (EP) flux E)

$$
F=F_{R}+F_{g}=\frac{1}{\rho_{o} a \cos \phi} \nabla \cdot E
$$

where the meridional and vertical components of $E$ are

$$
\begin{aligned}
& E_{y}=\rho_{o} a \cos \phi\left[\frac{\partial \bar{u} / \partial z}{\partial \bar{\theta} / \partial z} \overline{v^{\prime} \theta^{\prime}}-\overline{u^{\prime} v^{\prime}}\right] \\
& E_{z}=\rho_{o} a \cos \phi\left[\frac{\eta}{\partial \bar{\theta} / \partial z} \overline{v^{\prime} \theta^{\prime}}-\overline{u^{\prime} w^{\prime}}\right]
\end{aligned}
$$

Equations (1) to (4) can be combined to give a diagnostic equation for the mean meridional stream function [Garcia and Solomon, 1983]

$C_{y y} \frac{\partial^{2} \chi}{\partial y^{2}}+C_{y z} \frac{\partial^{2} \chi}{\partial y \partial z}+C_{z z} \frac{\partial^{2} \chi}{\partial z^{2}}+C_{y} \frac{\partial \chi}{\partial y}+C_{z} \frac{\partial \chi}{\partial z}=C_{F} \cos \phi$

where the "velocity" stream function $\chi$ and the "mass" stream functions $\psi$ are related to the components of the mean meridional velocity by

$$
\begin{gathered}
\bar{v}^{*}=-\frac{1}{\rho_{o} \cos \phi} \frac{\partial}{\partial z}\left(\rho_{o} \chi\right)=-\frac{1}{\rho_{o} \cos \phi} \frac{\partial \psi}{\partial z} \\
\bar{w}^{*}=\frac{1}{\rho_{o} \cos \phi} \frac{\partial}{\partial y}\left(\rho_{o} \chi\right)=\frac{1}{\rho_{o} \cos \phi} \frac{\partial \psi}{\partial y}
\end{gathered}
$$

the equation coefficients $\left(C_{y y}, C_{y z}, C_{z z}, C_{y}\right.$, and $\left.C_{z}\right)$ are functions of the mean zonal wind and temperature distributions [Garcia and Solomon, 1983], and the forcing term $C_{F}$ is a function of the meridional gradient of the heating rate and the vertical gradient of the momentum torque associated with wave breaking:

$$
C_{F}=\frac{R}{H} \frac{\partial}{\partial y}\left(\bar{Q}-D_{\theta}\right)+f \frac{\partial F}{\partial z}
$$

Given the forcing term (to be described shortly), previous values of $\bar{\theta}$ (or $\bar{T}$ ) and $\bar{u}$, and the boundary conditions ( $\chi$ $=0$ at the poles, $\partial \chi / \partial z=0$ at the top and a specified value at the lower limit), equation (10) is solved by a 


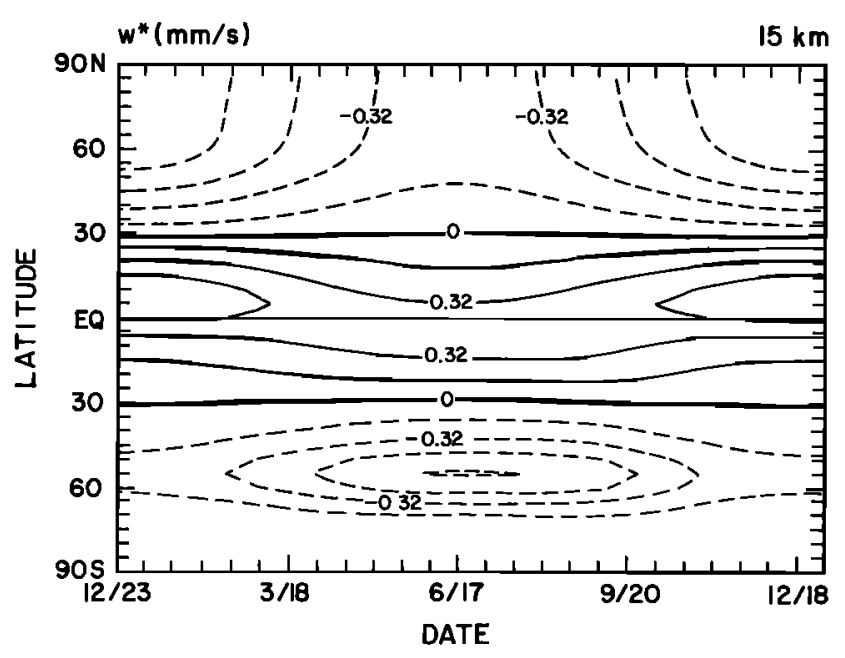

Fig. 1. Transformed Eulerian mean vertical velocity (in millimeters per second) specified at $\mathbf{1 5}$-km altitude (tropospheric forcing), as a function of latitude and season. Contour interval: 0.16 $\mathrm{mm} / \mathrm{s}$.

classical alternating direction method and provides the transformed Eulerian mean meridional circulation.

For the calculations of the dynamical quantities, the lower boundary is located at $15-\mathrm{km}$ altitude where the vertical velocity is specified as shown in Figure 1. (This condition, which simulates the dynamical forcing from the troposphere, is equivalent to a specified value of the stream function $\chi$.) Below $15 \mathrm{~km}$, where the formulation of mass and energy transport by the residual circulation is not straightforward because of the large transient and dissipative effects, the stream function is specified as a "return flow" to close up the two stratospheric meridional cells. Sensitivity calculations have shown that the structure of the temperature field as well as the slope of the mixing ratio isolines of the tracers in the lower stratosphere is very sensitive to the strength of the circulation specified at $15 \mathrm{~km}$. For example, the temperature minimum at the tropical tropopause changes by about $10 \mathrm{~K}$ if the wind velocity at the tropopause is modified by $50 \%$. Therefore we have tuned the values of the wind condition in order to obtain a temperature distribution in fair agreement with climatological values. This forcing varies with season and is different in each hemisphere. It should be noted that the use of a fixed dynamical boundary condition at $15 \mathrm{~km}$ and a "frozen" circulation and temperature below this level reduces the consistency of the model and limits the accuracy of calculated ozone perturbations in response to anthropogenic effects. This problem cannot be easily resolved, since the circulation in the lower stratosphere is driven by the wave forcing in the troposphere, a quantity that cannot be accurately estimated, especially in a two-dimensional model. Perhaps a way to improve the dynamical formulation in the lower stratosphere, with consistent mean circulation and wave driving (see below), is to determine both vertical velocity and wave activity in the troposphere from zonal mean climatological fields. At the present stage of the model development, an empirical wind condition determined to fit the observed ozone column and the temperature seems more appropriate.
Aside from the influence of the $15-\mathrm{km}$ boundary condition, the dynamical system is kept from radiative equilibrium conditions $\left(\bar{v}^{*}=\bar{w}^{*}=0 ; \bar{Q}=0\right)$ through momentum deposition associated with wave dissipation. In the present version of the model, only the effects of gravity waves and of Rossby waves are taken into account. The effect of equatorial waves will be included in a further developed version of the code in order to study additional large-scale phenomena such as the semiannual and the quasi-biennial oscillation of the atmosphere.

The contribution of gravity waves is parameterized by the scheme proposed by Lindzen [1981] and Holton [1982] and adopted by Garcia and Solomon [1985]. In this scheme, zonally traveling waves break when their amplitudes become so large that they become convectively unstable. Momentum deposition above the breaking level tends to accelerate (or decelerate) the zonal wind speed $\bar{u}$ toward the zonal phase speed $c$ of the wave. In the region between the breaking level $z_{b}$ and the critical level $z_{c}$ (where $\bar{u}=c$ ), wave amplitudes are assumed to cease their exponential growth with altitude and are reduced to a constant profile by convective turbulence. The body force transferred from the waves to the local mean flow is given by

$$
F_{g}=B(c-\bar{u})^{2}\left[(c-\bar{u})+3 H \frac{\partial \bar{u}}{\partial z}\right]
$$

in the range $z_{b}<z<z_{c}$, where the breaking level is determined by

$$
z_{b}=3 H \ln \left[\frac{|c-\bar{u}|}{\tilde{u}}\right]
$$

and where $H$ is the scale height. Parameters $B$ and $\tilde{u}$, which represent wave properties at $15 \mathrm{~km}$ (see, for example, Brasseur and Hitchman [1987]) are specified in Table 1 for the spectrum of phase speeds used in the present study. The values of these parameters have been adjusted to make the calculated body force consistent with the momentum budget of the middle atmosphere established for mid-December 1978 from the limb infrared monitor of the stratosphere (LIMS) observations [Hitchman and Leovy, 1986]. The algorithm then was applied at all times. According to the parameterization of Lindzen, the vertical eddy diffusion coefficient associated with gravity wave breaking above the $z_{b}$ level is given by

$$
K_{z z}=\frac{B}{N^{2}}(c-\bar{u})^{3}\left[(c-\bar{u})+3 H \frac{\partial \bar{u}}{\partial z}\right]
$$

Profiles of $F_{g}$ and $K_{z z}$ are smoothed in the vertical to avoid numerical problems when solving the transport

TABLE 1. Parameters Adopted for the Calculation of Wave Drag and Eddy Diffusion Associated with Gravity Wave Breaking

\begin{tabular}{ccc}
\hline$c, \mathrm{~m} / \mathrm{s}$ & $B, 10^{-9} \mathrm{~s} / \mathrm{m}^{2}$ & $\bar{u}, \mathrm{~m} / \mathrm{s}$ \\
\hline-40 & 0.5 & 3.0 \\
-20 & 1.0 & 3.0 \\
0 & 2.0 & 3.0 \\
+20 & 1.0 & 3.0 \\
+40 & 0.5 & 3.0 \\
\hline
\end{tabular}


equations. A background value of $0.1 \mathrm{~m}^{2} / \mathrm{s}$ is added and accounts for all additional processes not included in Lindzen's formulation.

To determine the momentum deposition rate as well as eddy coefficients associated with planetary wave breaking, an equation for Rossby wave activity is added to the system. According to Edmon et al. [1980] and Hitchman and Brasseur [1988], Rossby wave activity $A$ is conserved following the WKBJ group velocity $G$ unless there are sources or sinks; so that

$$
\frac{\partial A}{\partial t}+\frac{1}{\cos \phi} \frac{\partial}{\partial y}\left(\cos \phi G_{y} A\right)+\frac{\partial}{\partial z}\left(G_{z} A\right)=-\alpha A
$$

This equation can be solved provided that the meridional and vertical components of the group velocity $\left(G_{y}\right.$ and $G_{z}$ ) as well as the wave damping rate $\alpha$ are known and that proper boundary conditions are specified. Hitchman and Brasseur [1988], using the dispersion relation for quasi-stationary undamped waves on the beta plane, have derived an expression for the group velocity components as a function of the mean zonal state of the atmosphere. Given a source of wave activity at $15-\mathbf{k m}$ altitude, based on climatological values and accounting for the tropospheric forcing of the planetary waves, and using a damping rate

$$
\alpha(z)=0.7+0.6 \tanh \left[\frac{(z(k m)-50)}{15}\right] \mathrm{day}^{-1}
$$

intended to represent the effects of radiative and mechanical damping on Rossby waves, equation (16) is solved through an alternating direction method. The upper boundary condition is $A=0$, while $\partial A / \partial y=0$ is specified at the poles. The components of the Eliassen-Palm flux, from which the body force can easily be calculated, are then given by the simple linear wave approximation [Hitchman and Brasseur, 1988]

$$
\begin{aligned}
& E_{y}=G_{y} A \\
& E_{z}=G_{z} A
\end{aligned}
$$

Since for quasi-geostrophic Rossby waves, the meridional flux of eddy potential vorticity $\left.\overline{\left(v^{\prime} q^{\prime}\right.}\right)$ is proportional to the divergence of the quasi-geostrophic EP flux [Edmon et al., 1980], the mixing coefficient for potential vorticity (q) can be derived from the following expression

$$
K_{y y}=-\frac{\nabla \cdot E}{\rho_{o} a \cos \phi \partial \bar{q} / \partial y}
$$

Thus in this formulation the dissipative processes responsible for wave driving are also responsible for irreversible mixing of potential vorticity. As discussed by Hitchman and Brasseur [1988], the values of $K_{y y}$ derived from (18) for potential vorticity are generally applicable to chemically active tracers. If the lifetime of the tracer is similar to that of potential vorticity or if mechanical dissipation dominates, $K_{y y}$ can be used for the tracer. If the tracer concentration is photochemically controlled, the behavior of the species is insensitive to the value of $K_{y y}$. If Rossby wave activity is primarily radiatively damped and if simultaneously the tracer lifetime is much larger than that for potential vorticity, then other values of $K_{y y}$ should be determined for the tracer. In this study we assume that $K_{y y}$ and $K_{z z}$ derived from the formulations described in this paper apply to all variables.

The temperature distribution is derived from the thermodynamic equation (1) in which the contribution of the small-scale eddies $\left(D_{\theta}\right)$ is assumed to be related to vertical eddy exchanges, so that $D_{\theta}$ is parameterized by

$$
D_{\theta}=\frac{1}{\rho_{o}} \frac{\partial}{\partial z}\left[\rho_{o} K_{z z} \frac{\partial \bar{\theta}}{\partial z}\right]
$$

where $K_{z z}$ includes the diffusivity associated with gravity wave breaking.

\subsection{Radiation}

The net diabatic heating rate $Q$ is calculated from the detailed radiative code used in the latest version of the National Center for Atmospheric Research (NCAR) community climate model (CCM1) [Kiehl et al., 1987]. The routines include the absorption of solar radiation by several trace gases: the contribution of ozone in the ultraviolet and visible is calculated following Lacis and Hansen [1974], the effect of water vapor in the nearinfrared is derived from the parameterization of Kratz and Cess [1985] for the direct beam and the formulation of Lacis and Hansen [1974] for the reflected beam, and the effect of carbon dioxide in the near-infrared is calculated from the formulation of Sasamori et al. [1972]; finally, the contribution of molecular oxygen in the near-infrared is determined from the parameterization of Kiehl and Yamanouchi [1985]. The radiative transfer equation is solved for two large spectral regions: $0-0.9 \mu \mathrm{m}$ and 0.9 $4.0 \mu \mathrm{m}$, respectively. The 24-hour average of the solar heating is calculated consistently with the method used to derive the 24 hour average of the photodissociation coefficients. In the present version of the model, the effect of clouds is ignored, and the surface albedo at all wavelengths is taken to be 0.1 . The ground temperature is specified by climatological values. However, since the dynamics in the model is calculated interactively only above the tropopause, the temperature calculated below $10 \mathrm{~km}$ is replaced by climatological values compiled by Randel [1987]. A linear interpolation between calculated and climatological values is performed between 10 and $15 \mathrm{~km}$.

The integration of the thermodynamic equation, which provides the distribution of the zonally averaged temperature, is split in to two successive steps and performed by an alternating direction algorithm [Peaceman and Rachford, 1955]. This method is also used to solve the trace species equation (see the appendix). A comparison with other numerical techniques (purely explicit, positive definite advection scheme (Smolarkiewicz [1983], among others)) shows that this "splitting" method is computationally efficient and stable even for long time steps [Pirre and Delannoy, 1989]. The solutions are very close to the values obtained by the other methods (e.g., the explicit method, which is known to be accurate but requires very small time steps), and mass and energy appear to be reasonably well conserved even after several years of integration. The entire system is stable for a time step of 15 days, which is used when the integration is performed for periods longer than a season. This enables many long- 
term scenarios to be calculated with detailed radiative, chemical, and dynamical codes in a rapid and accurate manner.

\subsection{Chemistry}

The model includes about 35 chemical species. For those which have a long chemical lifetime and are therefore sensitive to dynamics and chemistry, a full continuitytransport equation is solved

$$
\begin{gathered}
\frac{\overline{\partial X_{i}}}{\partial t}+\overline{v^{*}} \frac{\overline{\partial X_{i}}}{\partial y}+\overline{w^{*}} \frac{\overline{\partial X_{i}}}{\partial z}=\overline{S_{i}} \\
+\frac{1}{\cos \phi} \frac{\partial}{\partial y}\left(\cos \phi K_{y y} \overline{\frac{\partial X_{i}}{\partial y}}\right)+\frac{1}{\rho_{o}} \frac{\partial}{\partial z}\left(\rho_{o} K_{z z} \overline{\frac{\partial X_{i}}{\partial z}}\right)
\end{gathered}
$$

where $S_{i}$ is the net source term accounting for all chemical and photochemical processes involved in the formation and destruction of a given constituent $i$. In this equation the off-diagonal components of the diffusion matrix ( $K_{y z}$ and $K_{z y}$ ) have been deliberately omitted. As was shown by Smith et al. [1988] in the case of ozone, the horizontal eddy transport associated with planetary wave is dominated by the $K_{y y}$ term. Similarly, the largest contribution to vertical eddy transport is due to the $K_{z z}$ term associated with gravity wave breaking. Jackman et al. [1988], however, have shown that the concentration of source gases such as $\mathrm{N}_{2} \mathrm{O}$ could be sensitive to $K_{y z}$, especially in the middle stratosphere, at high latitudes in winter. Values derived for $K_{y z}$ and for its seasonal variation are very uncertain, so that the introduction of

TABLE 2. Species or Family of Species for Which

\begin{tabular}{|c|c|c|c|}
\hline & & \multicolumn{2}{|c|}{ Boundary Condition } \\
\hline & & $0 \mathrm{~km}$ & $85 \mathrm{~km}$ \\
\hline 1 & $\mathrm{~N}_{2} \mathrm{O}$ & $X=3.1 E-7^{*}$ & $\Phi=0$ \\
\hline 7 & $\mathrm{CH}_{4}$ & $X \simeq 1.6 E-6 \dagger$ & $\Phi=0$ \\
\hline 2 & $\mathrm{CCl}_{4}$ & $X=1.2 E-10$ & $\Phi=0$ \\
\hline 3 & $\mathrm{CFCl}_{3}$ & $X=2.2 E-10$ & $\Phi=0$ \\
\hline 4 & $\mathrm{CF}_{2} \mathrm{Cl}_{2}$ & $X=4.2 E-10$ & $\Phi=0$ \\
\hline 5 & $\left.\mathrm{CH}_{3} \mathrm{CC}\right)_{3}$ & $X=1.7 E-10$ & $\Phi=0$ \\
\hline 6 & $\mathrm{CH}_{3} \mathrm{Cl}$ & $X=7.0 E-10$ & $\Phi=0$ \\
\hline 8 & $\mathrm{C}_{2} \overline{\mathrm{H}}_{2}$ & $X=3.0 E-10$ & $\Phi=0$ \\
\hline 9 & $\mathrm{C}_{2} \mathrm{H}_{6}$ & $X=1.5 E-9$ & $\Phi=0$ \\
\hline 10 & $\mathrm{C}_{3} \mathrm{H}_{8}$ & $X=2.5 E-10$ & $\Phi=0$ \\
\hline 11 & HCN & $X=2.2 E-10$ & $\Phi=0$ \\
\hline 12 & $\mathrm{CH}_{3} \mathrm{CN}$ & $X=2.0 E-10$ & $\Phi=0$ \\
\hline 13 & $\mathrm{H}_{2} \mathrm{O}$ & see text & $\Phi=1.0 \mathrm{E}+8$ \\
\hline 14 & $\mathrm{H}_{2}$ & $X=5.5 E-7$ & $\Phi=5.0 \mathrm{E}+7$ \\
\hline 15 & $\mathrm{CO}$ & $X \simeq 1.0 E-7^{\dagger}$ & $\Phi=0$ \\
\hline 16 & $\mathrm{CO}_{2}$ & $X=3.4 E-4$ & $\Phi=0$ \\
\hline 18 & $\mathrm{NO}_{y}$ & $X=3.0 E-10$ & $X=2.0 \mathrm{E}-7$ \\
\hline 19 & $\mathrm{HNO}_{3}$ & $X=1.0 E-10$ & $\Phi=0$ \\
\hline 20 & $\mathrm{~N}_{2} \mathrm{O}_{5}$ & $X=1.0 E-15$ & $\Phi=0$ \\
\hline 21 & $\mathrm{Cl}_{x}$ & $X=1.0 E-10$ & $\Phi=0$ \\
\hline 22 & H & $X=0$ & $X=1.0 \mathrm{E}-6$ \\
\hline 23 & $\mathrm{O}_{x}$ & $W_{D}=0.1$ & $\Phi=0$ \\
\hline
\end{tabular}
a Continuity Equation is Solved

Adopted boundary conditions are given at the Earth surface $(0 \mathrm{~km})$ and at the mesopause $(85 \mathrm{~km}) . X$ is mixing ratio; $\Phi$ is flux $\left(\mathrm{cm}^{-2} \mathrm{~s}^{-1}\right) . W_{D}$ is deposition velocity $\left(\mathrm{cm} \mathrm{s}^{-1}\right.$. Species in photochemical equilibrium or whose concentration is derived from a transported family are $\mathrm{O}_{3}, \mathrm{O}\left({ }^{3} \mathrm{P}\right), \mathrm{O}\left({ }^{1} \mathrm{D}\right), \mathrm{OH}, \mathrm{HO}_{2}, \mathrm{CH}_{3} \mathrm{O}_{2}, \mathrm{~N}, \mathrm{NO}_{2}$, $\mathrm{NO}_{3}, \mathrm{HO}_{2} \mathrm{NO}_{2}, \mathrm{Cl}, \mathrm{ClO}, \mathrm{HOCl}, \mathrm{HCl}$, and $\mathrm{ClONO}_{2}$.

* Read $3.1 E-7$ as $3.1 \times 10^{-7}$.

${ }^{\dagger}$ Variable with latitude. this component would not improve the validity of the results.

For the short-lived chemical species with a lifetime shorter than the dynamical time constants, photochemical equilibrium conditions apply and the concentration of trace gas $i$ is derived from an algebraic equation $\overline{S_{i}} \overline{\left(X_{i}\right)}$ $=\mathrm{O}$. Table 2 gives a list of the constituents for which a continuity is solved (and the boundary conditions imposed on these species) as well as of those which are assumed to be in photochemical equilibrium. The different reactions introduced in the model with the related reaction rates based on the Jet Propulsion Laboratory (JPL) 1985 compilation [DeMore et al., 1985] are given in Tables $3 a$, $3 b$, and $3 c$. The absorption cross sections used for the calculation of the photodissociation coefficients are very similar to the values suggested in the JPL 1985 tables. Values of the solar irradiance are from Brasseur and Simon [1981].

In order to avoid mathematically stiff systems due to the large dispersion in the lifetime of the several species, some of the fast-reacting constituents are grouped into more stable families for which a full continuity equation (20) is solved. In our model, the following families have been formed: $\mathrm{O}_{x}=\mathrm{O}_{3}+\mathrm{O}\left({ }^{3} \mathrm{P}\right)+\mathrm{O}\left({ }^{1} \mathrm{D}\right), \mathrm{NO}_{y}$ $=\mathrm{N}+\mathrm{NO}+\mathrm{NO}_{2}+2 \mathrm{~N}_{2} \mathrm{O}_{5}+\mathrm{NO}_{3}+\mathrm{HNO}_{3}+$ $\mathrm{HO}_{2} \mathrm{NO}_{2}+\mathrm{ClONO}_{2}$, and $\mathrm{Cl}_{x}=\mathrm{Cl}+\mathrm{ClO}+\mathrm{HCl}$ $+\mathrm{HOCl}+\mathrm{ClONO}_{2}$. It should be noted that $\mathrm{HNO}_{3}$ and $\mathrm{N}_{2} \mathrm{O}_{5}$ are also calculated independently from the $\mathrm{NO}_{y}$ family because of their weak coupling with the other odd nitrogen species, particularly at high latitude and in winter. The water vapor is transported in the stratosphere, but in the troposphere the relative humidity is prescribed according to Cess [1976] and the mixing ratio of $\mathrm{H}_{2} \mathrm{O}$ is calculated as a function of the local temperature and pressure. The concentration of the individual fastreacting species belonging to a given family are derived using relations based on the assumption of photochemical equilibrium.

\section{Model Results and Discussion}

The model provides a large amount of output for different times of the year, and therefore only selected results (primarily for solstice conditions) will be presented and discussed. Additional results will be given in subsequent papers in which specific problems will be considered.

\subsection{Radiation and Dynamics}

The deposition of energy in the stratosphere arises primarily from the absorption of solar radiation by the Hartley band of ozone $(200-300 \mathrm{~nm})$. The heating rate peaks near $50 \mathrm{~km}$ altitude with a maximum value (12.3 $\mathrm{K} /$ day) over the summer pole (see Figure 2a). At the equator, the 24 hour averaged heating rate reaches a maximum value of about $10 \mathrm{~K} /$ day. The radiative heating of the cloudless troposphere is due primarily to the radiative action of water vapor and the corresponding diabatic heating rate in this layer, where strong convective exchanges take place is only of the order of $1 \mathrm{~K} /$ day or less. At present, however, as was indicated earlier, tropospheric temperatures are specified from a climatology compiled by Randel [1987]. The contribution of molecular oxygen, which absorbs ultraviolet radiation at wavelengths shorter than $242 \mathrm{~nm}$, remains smaller than about 1 
TABLE 3a. Chemical Reactions Included in the Model and Corresponding Rate Constants

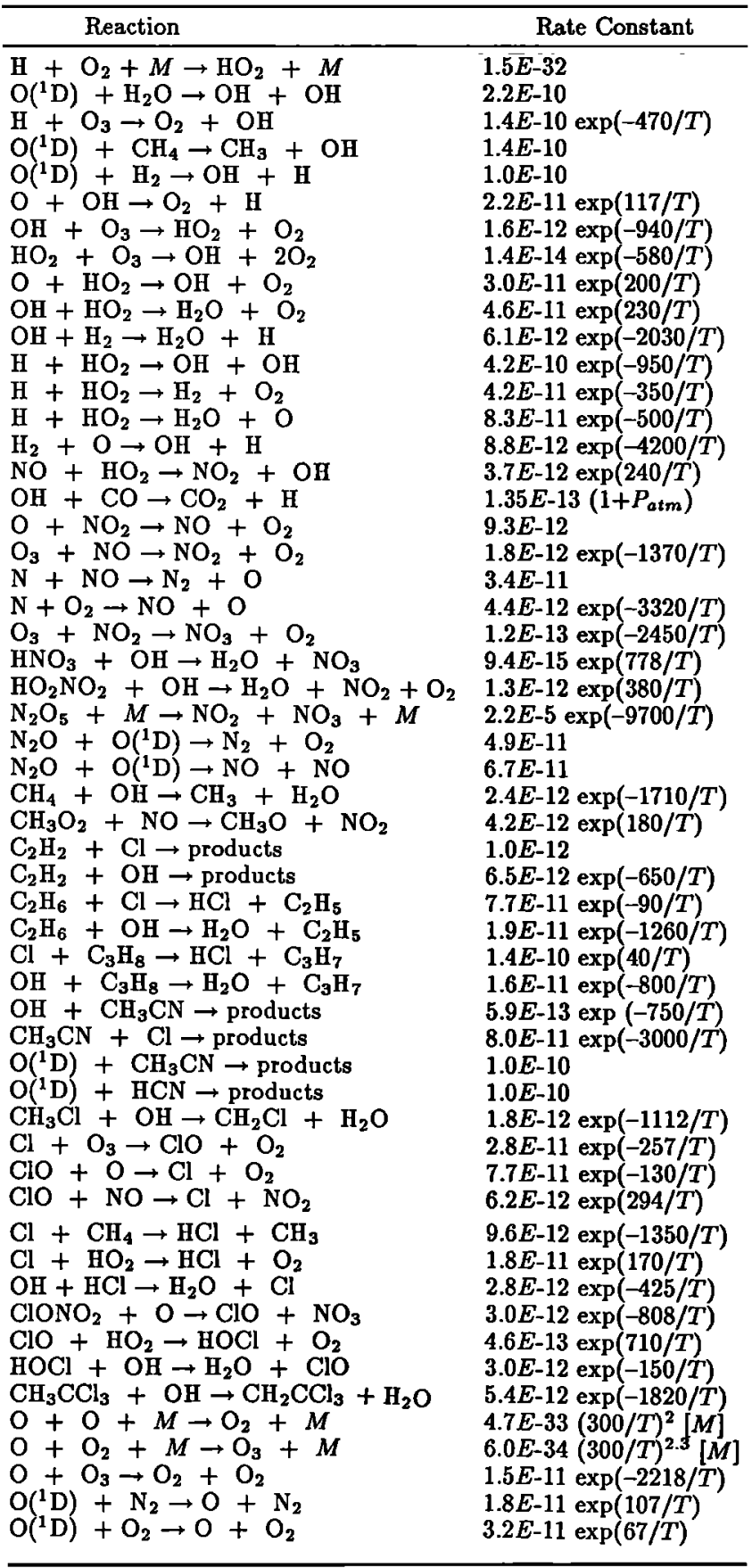

E-11 corresponds to $10^{-11} . T$ is the temperature $(\mathrm{K}),[M]$ is the atmospheric density $\left(\mathrm{cm}^{-3}\right), P_{\text {atm }}$ is the pressure expressed in atmosphere.

$\mathrm{K} /$ day below the mesopause, although this constituent is the largest contributor to solar heating in the upper mesosphere. The cooling (Figure 2b) resulting from the emission of infrared radiation by carbon dioxide, ozone, and water vapor is nearly in balance with the solar heating in the illuminated part of the atmosphere. In these regions the temperatures calculated by the model are similar to radiative equilibrium conditions. In the polar region during winter, when no solar light is available, the cooling (of as much as $7 \mathrm{~K} / \mathrm{day}$ at 60 -
TABLE 36. Three-Body Reaction With the Following Expressions for Their Rate Constant $k\left(\mathrm{~cm}^{3} \mathrm{~s}^{-1}\right)$

\begin{tabular}{lll}
\hline & Rate & Exponent \\
\hline $\mathrm{NO}_{3}+\mathrm{NO}_{2}+M \rightarrow \mathrm{N}_{2} \mathrm{O}_{5}+M$ & $\kappa_{0}^{300}=2.2 E-30$ & $n=2.8$ \\
& $\kappa_{\infty}^{300}=1.0 E-12$ & $m=0$ \\
$\mathrm{NU}_{2}+\mathrm{OH}+M \rightarrow \mathrm{HNO}_{3}+M$ & $\kappa_{0}^{300}=2.6 E-30$ & $n=2.9$ \\
& $\kappa_{\infty}^{300}=2.4 E-11$ & $m=1.3$ \\
$\mathrm{NO}_{2}+\mathrm{HO}_{2}+M \rightarrow \mathrm{HO}_{2} \mathrm{NO}_{2}+M$ & $\kappa_{o}^{300}=2.3 E-31$ & $n=4.6$ \\
& $\kappa_{\infty}^{300}=4.2 E-12$ & $m=0$ \\
$\mathrm{ClO}^{30} \mathrm{NO}_{2}+M \rightarrow \mathrm{ClONO}_{2}+M$ & $\kappa_{o}^{300}=1.8 E-31$ & $n=3.4$ \\
& $\kappa_{\infty}^{300}=1.5 E-11$ & $m=1.9$
\end{tabular}

The rate constant is derived by $k=\left[\kappa_{o}[M] /\left(1+\kappa_{o}[M] / \kappa_{\infty}\right)\right]$ $0.6^{\left\{1+\left[\log _{10}\left(\kappa_{0}[M] / \kappa_{\infty}\right)\right]^{2}\right\}^{-1}}$ with $\kappa_{o}=\kappa_{0}^{300}(T / 300)^{-n}$ and $\kappa_{\infty}=\kappa_{\infty}^{300}$ $(T / 300)^{-m}$.

km altitude) is counterbalanced by compressional heating through substantial downward motion of air. In the lower stratosphere, where the radiative time constant is larger than 10 days, the meridional circulation plays a dominant role in establishing the temperature distribution.

The meridional distribution of the temperature obtained by solving the thermodynamic equation, in which radiative transfer and heat transport are included explicitly, is shown in Figure $2 c$ for June conditions. The stratopause maximum near $50-\mathrm{km}$ altitude reaches a valne of nearly $284 \mathrm{~K}$ over the summer pole but gradually decreases toward the winter pole. In the mesosphere the latitudinal gradient in the temperature is reversed as a consequence of momentum drag by gravity waves. The temperature at the mesopause is of the order of $170 \mathrm{~K}$ over the summer pole and $220 \mathrm{~K}$ over the winter pole. With the adopted boundary conditions, a temperature minimum of about $205 \mathrm{~K}$ is derived at the tropopause over the tropics. There are differences between the two hemispheres for the

TABLE 3c. Photochemical Reactions Included in the Model

\begin{tabular}{|c|c|}
\hline & Reaction \\
\hline $\begin{array}{l}J\left(\mathrm{O}_{2}\right) \\
J^{*}\left(\mathrm{O}_{2}\right) \\
J\left(\mathrm{O}_{3}\right) \\
J^{*}\left(\mathrm{O}_{3}\right) \\
J\left(\mathrm{H}_{2} \mathrm{O}\right) \\
J\left(\mathrm{~N}_{2} \mathrm{O}\right) \\
J\left(\mathrm{CO}_{2}\right) \\
J\left(\mathrm{CH}_{4}\right) \\
J\left(\mathrm{NO}_{2}\right) \\
J\left(\mathrm{HNO}_{3}\right) \\
J\left(\mathrm{CF}_{2} \mathrm{Cl}_{2}\right) \\
J\left(\mathrm{CFCl}_{3}\right) \\
J\left(\mathrm{CCl}_{4}\right) \\
J(\mathrm{HOCl}) \\
J\left(\mathrm{CH}_{3} \mathrm{CCl}_{3}\right) \\
J\left(\mathrm{HO}_{2} \mathrm{NO}_{2}\right) \\
J\left(\mathrm{CH}_{3} \mathrm{Cl}\right) \\
J\left(\mathrm{ClONO}_{2}\right) \\
J\left(\mathrm{~N}_{2} \mathrm{O}_{5}\right) \\
J\left(\mathrm{NO}_{3}\right)\end{array}$ & 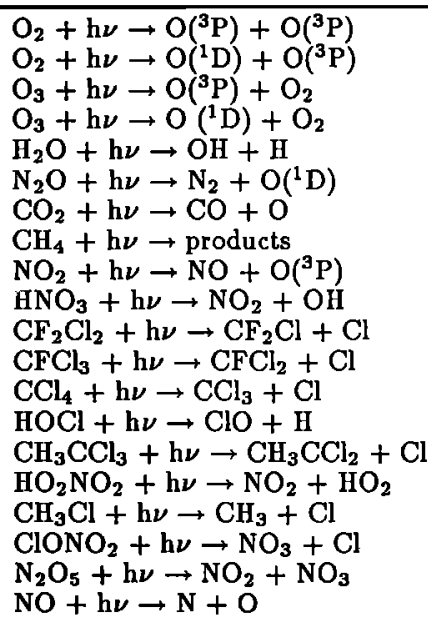 \\
\hline
\end{tabular}



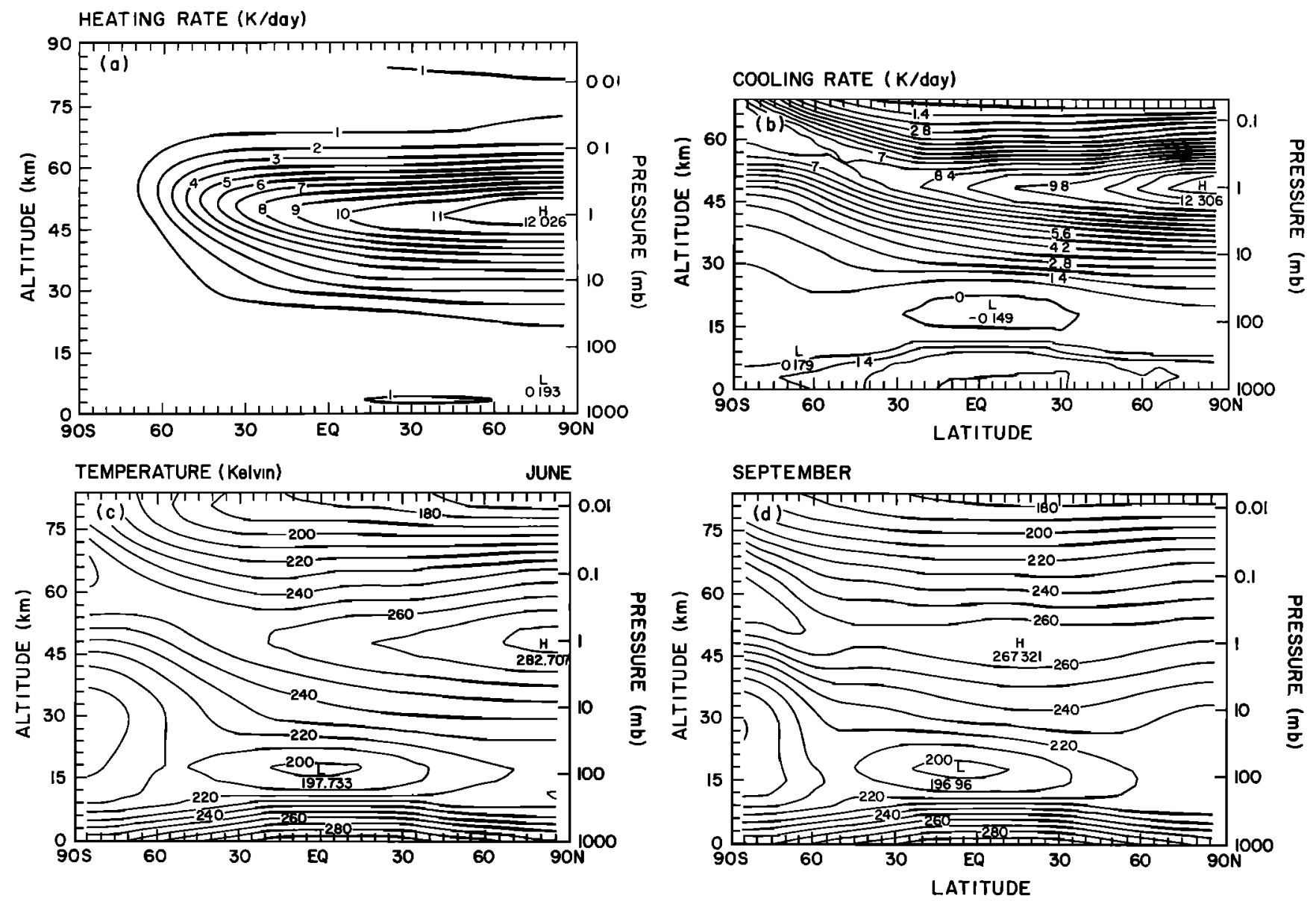

Fig. 2. Meridional distribution of (a) the solar heating rate and (b) the infrared cooling rate expressed in Kelvins per day (June conditions), and meridional distribution of the zonally averaged temperature (expressed in Kelvins), $(c)$ in June and $(d)$ in September. Contour intervals: $1 \mathrm{~K} /$ day (Figure $2 a$ ), $0.7 \mathrm{~K} /$ day (Figure $2 b$ ), and $10 \mathrm{~K}$ (Figures $2 c$ and $2 d$ ).

same season, those being direct consequences of the latitudinal asymmetry in the specified dynamical conditions at the $15-\mathrm{km}$ boundary. For example, the temperature in the lower stratosphere $(20 \mathrm{~km})$ is of the order of 185 . $190 \mathrm{~K}$ over Antarctica in September (Figure 2d) but is nearly $10 \mathrm{~K}$ warmer over the Arctic 6 months later. This difference between the two hemispheres is consistent with climatological data and explains the more frequent presence and the different nature of polar stratospheric clouds in winter over Antarctica than over the Arctic.

The zonal wind, in gradient balance with the temperature, is shown for June and September in Figures $3 a$ and $3 b$. For solstice conditions, the westerly wind in the southern hemisphere (winter) reaches a velocity of $90 \mathrm{~m} / \mathrm{s}$ near the stratopause at $60^{\circ}$. In the northern hemisphere (summer) the easterly winds are a factor of 2 weaker (about $40 \mathrm{~m} / \mathrm{s}$ in the upper stratosphere and in the mesosphere). In September the model produces a strong polar vortex in the southern hemisphere with a maximum wind velocity of $100 \mathrm{~m} / \mathrm{s}$ near the stratopause between $60^{\circ}$ and $70^{\circ}$ latitude. A substantially weaker stratospheric jet is found 6 months later in the springtime northern hemisphere (not shown) with maximum wind speed of $88 \mathrm{~m} / \mathrm{s}$.

The momentum sources from gravity and Rossby wave absorption are shown in Figures $4 a$ and $4 b$, respectively. A large easterly torque of more than $100 \mathrm{~m} \mathrm{~s}^{-1} /$ day is derived in the winter mesosphere, while a westerly drag of up to $50 \mathrm{~m} \mathrm{~s}^{-1} /$ day is calculated in the summer mesosphere, as a result of gravity wave breaking. Momentum deposition due to Rossby waves is produced only in the winter hemisphere since the upward propagation of these waves requires the presence of westerly winds. The Eliassen-Palm flux, which is shown by the arrows in Figure $4 b$, is directed upward and toward the equator. The torque associated with Rossby wave absorption is for this particular case in the range 0.5 to $6 \mathrm{~m} \mathrm{~s}^{-1} /$ day in the latitudinal band of $30^{\circ}$ to $60^{\circ}$. The eddy diffusion coefficients used in the transport scheme of the model and derived from the parameterization of wave breaking are shown for June conditions in Figures $4 c$ and $4 d$. The vertical eddy diffusivity, as derived from the gravity wave formulation, is characterized by a strong vertical gradient in the stratosphere. $K_{z z}$ coefficients of the order of 1 to $70 \mathrm{~m}^{2} / \mathrm{s}$ are calculated above the stratopause, with the highest values above the westerly jet core. In the lower stratosphere, below the breaking level of the waves, small background values of the order of $0.1 \mathrm{~m}^{2} / \mathrm{s}$ are adopted. In the troposphere, where rapid vertical mixing occurs, values of the order of $5-10 \mathrm{~m}^{2} / \mathrm{s}$ are specified with a variation in latitude to account for the varying height of the tropopause. The meridional diffusivity associated with planetary wave absorption for the particular case shown in Figure $4 d$ reaches values of the order of $(0.5-2.0) \times$ $10^{6} \mathrm{~m}^{2} / \mathrm{s}$ at mid-latitude. In the summer hemisphere, 

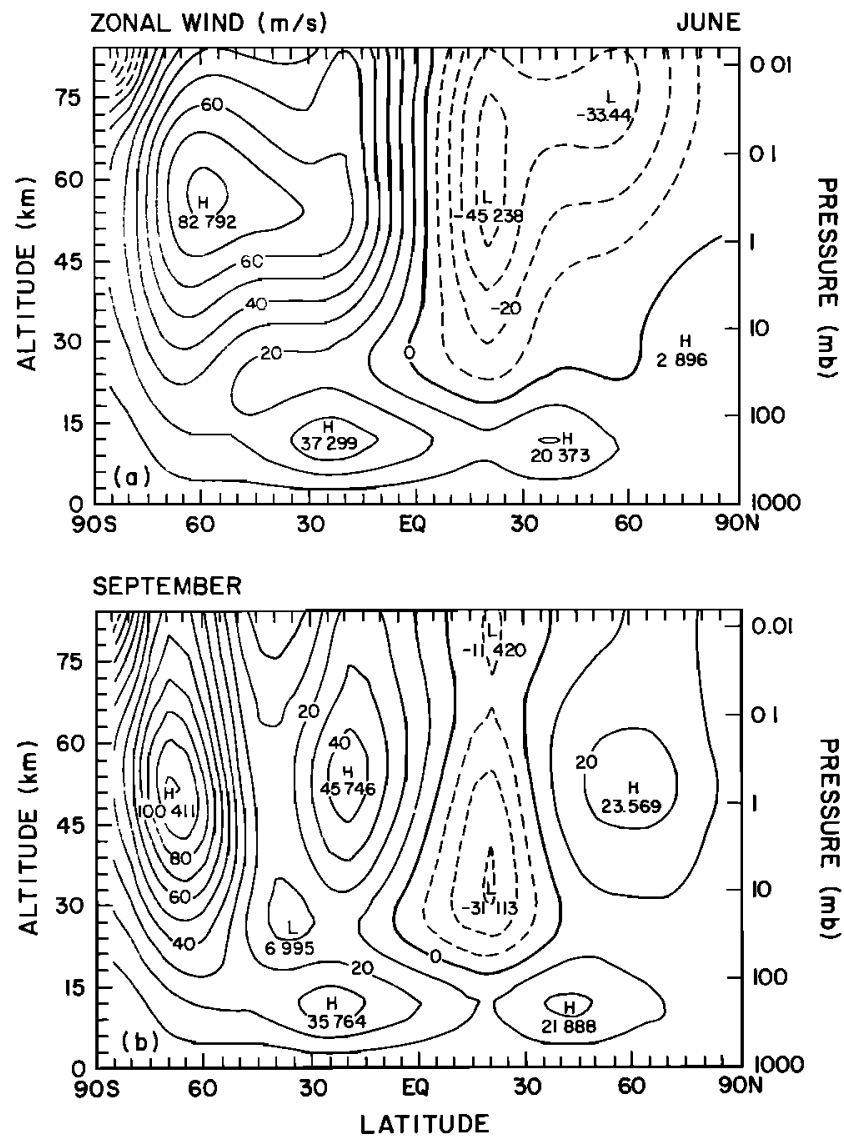

Fig. 3. Meridional distribution of the zonal wind (expressed in meters per second), $(a)$ in June and $(b)$ in September. Contour intervals: $10 \mathrm{~m} / \mathrm{s}$.

where no planetary waves penetrate, a background value of $3 \times 10^{5} \mathrm{~m}^{2} / \mathrm{s}$ is adopted to account for subgrid mixing processes.

Finally, the transformed mean Eulerian meridional circulation, driven by momentum drag associated with gravity and planetary wave dissipation, is shown in Figures $5 a$ and $5 b$ for June and September. The two stratospheric cells affecting the temperature and the density of trace gases in both hemispheres are clearly visible. Because the boundary conditions on the stream function specified at $15 \mathrm{~km}$ are not symmetric on each side of the equator, the flow in the northern hemisphere tends to transport mass and energy all the way to the pole in the northern hemisphere while it reaches only a region near $60^{\circ}-70^{\circ}$ latitude in the southern hemisphere. An important consequence of this hemispheric difference is that the model diagnoses the Antarctic region to be closer to radiative equilibrium conditions in winter than the Arctic during the same season. Because polar night temperatures over Antarctica are relatively cold, radiative cooling in this region is small. The net heating becomes transitorily positive and reaches about $0.3 \mathrm{~K} /$ day near $30-\mathrm{km}$ altitude, as the Sun returns over Antarctica in late winter. Since the vertical velocity specified at $15 \mathrm{~km}$ as boundary condition is zero over the region of the South Pole (see Figure 1), the model therefore predicts some upwelling during this short transition period but its strength, which is not large enough to deplete ozone significantly, is highly dependent on the ozone density in the lower polar stratosphere. This upward flow will be substantially reduced and even suppressed if ozone gets destroyed by chemical processes in late winter or early spring, as has been observed since the late 1970s (Farman et al. [1985] and others; see Solomon. [1988] or Brasseur et al., [1988a] for a review). A more refined analysis of the dynamical conditions in the polar regions in winter and spring requires a three-dimensional study describing exchanges between the troposphere and the stratosphere and accounting for the full interactions between chemistry, radiation, and dynamics. The present two-dimensional model, however, is capable of describing the net meridional transport in some detail and accounts for hemispheric differences in the tropospheric forcing of stratospheric dynamics.

\subsection{Chemistry}

The distribution of selected trace constituents will now be presented with the purpose of validating the model formulation. Figures $6 a$ and $6 b$ present the calculated distributions of nitrous oxide and methane for June conditions. In both cases the Hadley cell, through which these gases are transported from the troposphere into the stratosphere, produces the high mixing ratios over the tropics in the stratosphere. The meridional slope of the isomixing ratio contours between $15-$ and $40-\mathrm{km}$ altitude results from the opposing action of the meridional circulation (which tends to enhance the latitudinal gradients) and eddy diffusion (which tends to mix the trace gases along the quasi-horizontal isentropes) [see Holton, 1981]. Seasonal variations in the mixing ratio, driven by the Sun, can be seen in the upper stratosphere and mesosphere, where the photochemical time constant is smaller than the characteristic timescale for transport. Hence the effect of the chemistry is most pronounced in the summer hemisphere and is stronger for $\mathrm{N}_{2} \mathrm{O}$ than for $\mathrm{CH}_{4}$ as a result of the photochemical lifetime's being 10 times larger for $\mathrm{CH}_{4}$ than for $\mathrm{N}_{2} \mathrm{O}$ at $60 \mathrm{~km}$ and $60^{\circ} \mathrm{N}$ in June. The decrease with altitude of the mixing ratio in the mesosphere is reduced by vertical mixing resulting from gravity wave breaking. Since in our model, vertical eddy diffusivity is strongest near the core of the stratospheric jets and is substantially weaker in the tropics, a weak double peak structure appears occasionally in the meridional distribution of the source gases. Such a structure, to be comparable to the global observations of the stratospheric and mesospheric sounder (SAMS) instrument [Jones and Pyle, 1984], requires the presence of an additional momentum source located in the tropics. Gray and Pyle [1986] have attributed such a source to the absorption in the stratosphere of Kelvin waves. Finally, the distribution of the source gases in the mesosphere depends on the strength of the meridional circulation, which is directed from the summer to the winter hemisphere. The strength of this cell is determined by the momentum deposition of gravity waves in the mesosphere and upper stratosphere.

The distribution of water vapor in the middle atmosphere is shown in Figure 7a. In the lower stratosphere, where $\mathrm{H}_{2} \mathrm{O}$ is a purely conservative tracer, the slope of the mixing ratio lines is determined by the strength of the meridional flow. Clearly, the model underpredicts the mixing ratio of water vapor at high latitudes. A reason for the discrepancy between calculated and observed distributions could be an improper representation of transport processes in the vicinity of the tropopause (intrusion 

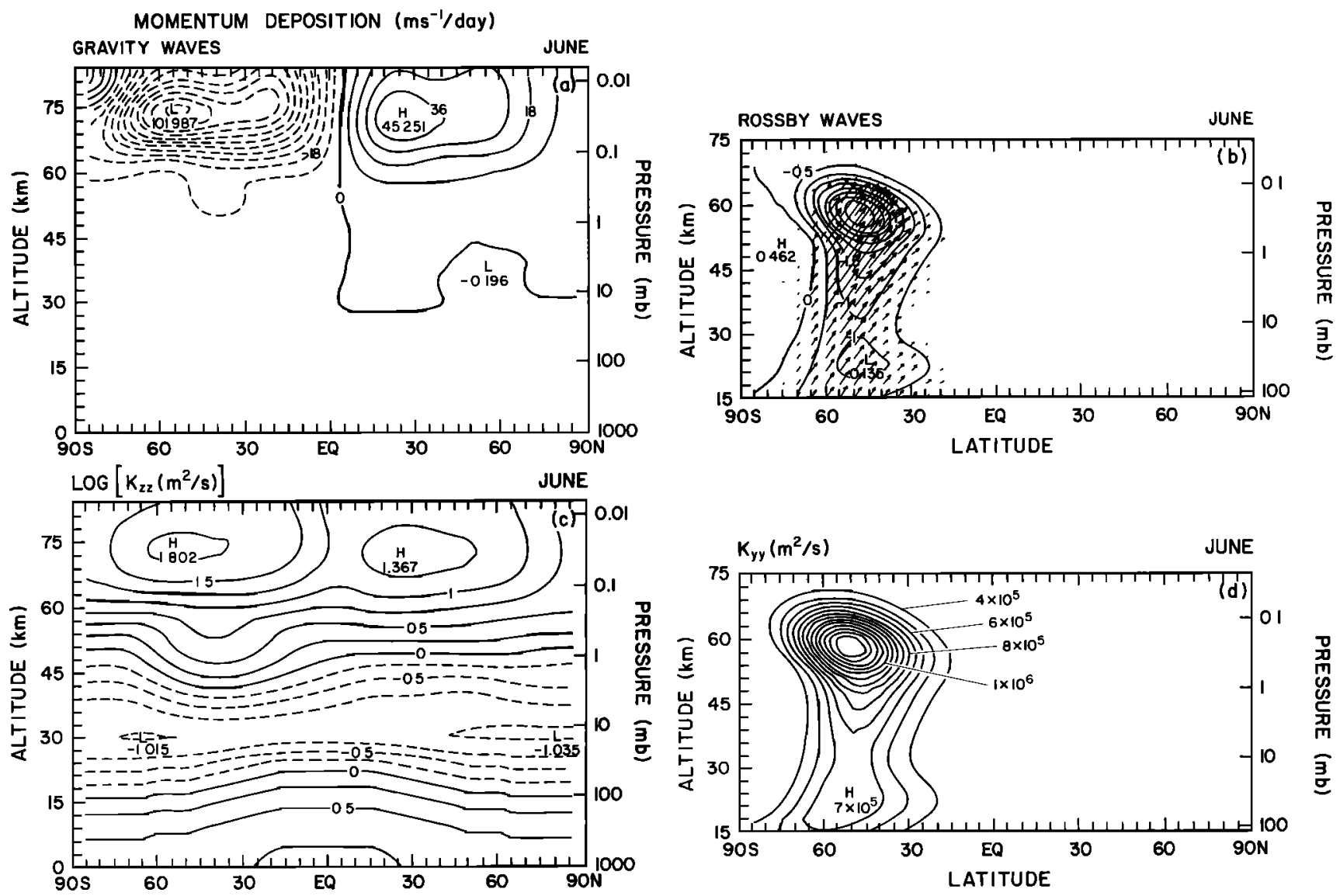

Fig. 4. Momentum deposition (expressed in $\mathrm{m} \mathrm{s}^{-1} /$ day) in June due to (a) gravity wave breaking and (b) Rossby wave absorption, and eddy diffusion coeflicients (expressed in $\mathrm{m}^{2} / \mathrm{s}$ ) associated with (c) gravity wave breaking and $(d)$ Rossby wave absorption. The vectors in Figure $4 b$ are proportional to the EliassenPalm flux (maximum vector length, $2.7 \times 10^{8} \mathrm{~kg} \mathrm{~m}^{-1} \mathrm{~s}^{-2}$ ). Note in the case of Figure $4 c$ that the diffusivity is represented by its decimal logarithm and that the specified tropospheric values are also represented. Contour intervals: $9 \mathrm{~m} \mathrm{~s}^{-1} /$ day (Figure 4a), $0.5 \mathrm{~m} \mathrm{~s}^{-1} /$ day (Figure 4b), 0.25 (Figure 4c), and $1 \times 10^{5} \mathrm{~m}^{2} / \mathrm{s}$

(Figure 4d).
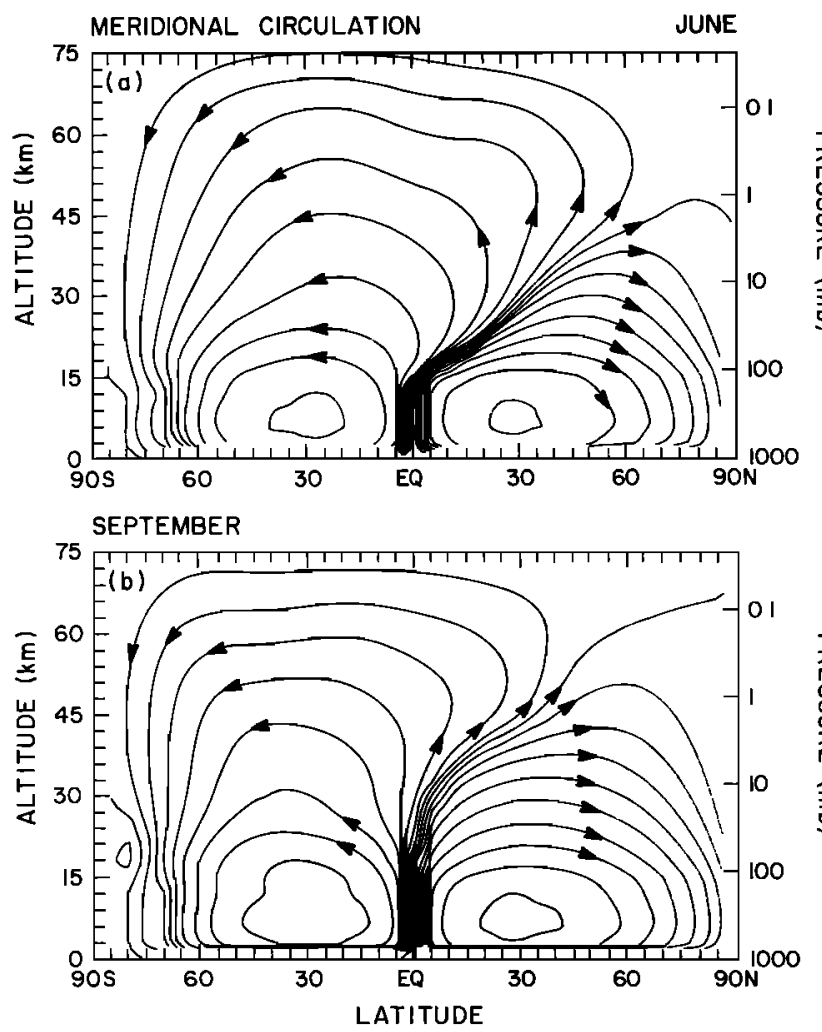

Fig. 5. Stream function of the transformed Eulerian mean meridional circulation in $(a)$ June and (b) September.
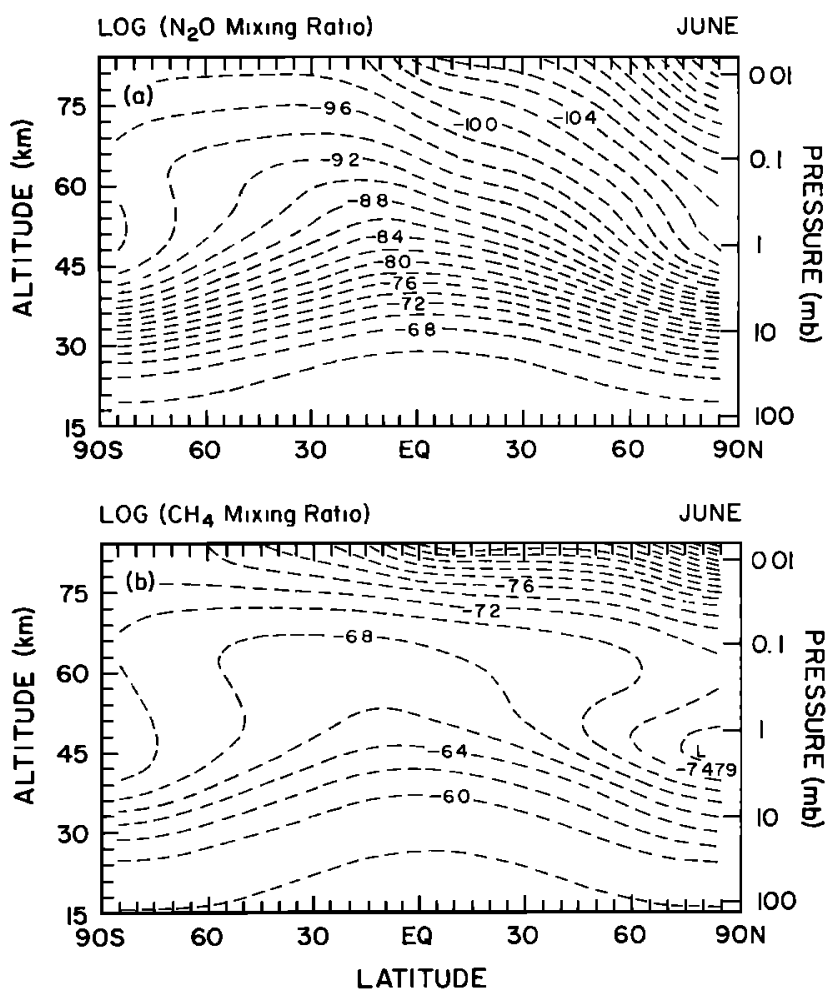

Fig. 6. Meridional distribution (June conditions) of the zonally averaged mixing ratio of $(a)$ nitrous oxide and $(b)$ methane. Contour intervals: 0.2 . 

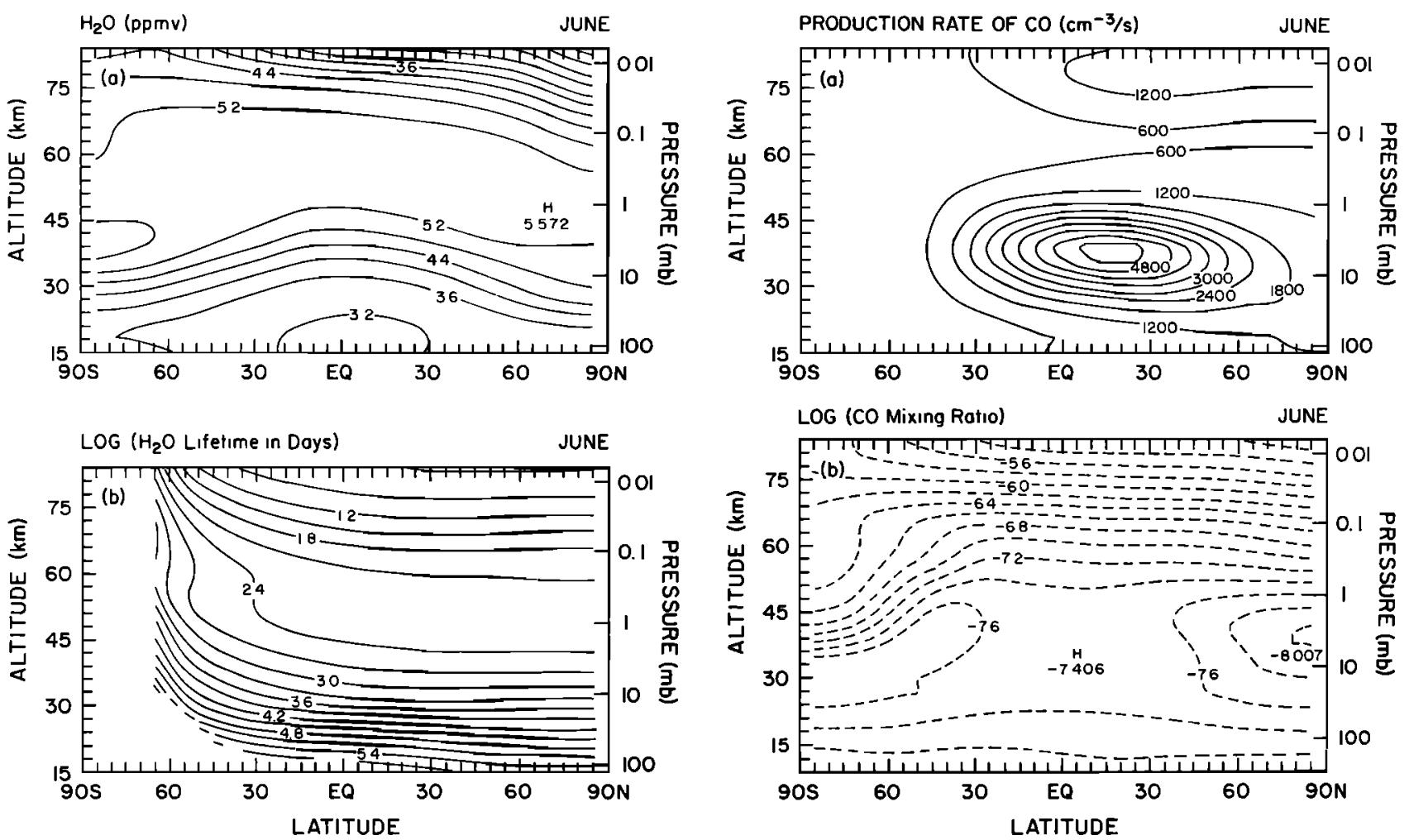

Fig. 7. Meridional distribution (June conditions) of (a) the zonally averaged mixing ratio and $(b)$ chemical lifetime of water vapor. The lifetime is represented by the decimal logarithm of its value expressed in days (e.g., 3 corresponds to 1000 days). Contour intervals: 0.4 ppmv (Figure $7 a$ ) and 0.3 (Figure $7 b$ ).

existence of a local source in the lower stratosphere at high latitudes [see LeTexier et al., 1988]. The increase with altitude of the water vapor mixing ratio above the tropopause is a direct consequence of the methane oxidation. The maximum concentration predicted by the model is found near the stratopause and is equal to 5.5 ppbv. In the mesosphere, water is photodissociated most effectively in summer. This process leads to the formation of atomic and molecular hydrogen. The decrease with altitude in the mixing ratio appears to be less pronounced in the model than is suggested by the observations using microwave techniques [Bevilacqua et al., 1985]. The lifetime of water vapor (see Figure $7 b$ ) is of the order of 3 years in the upper stratosphere and of the order of only 10 days in the upper mesosphere. Physical processes such as gravity wave breaking should affect substantially the local distribution of $\mathrm{H}_{2} \mathrm{O}$.

The behavior of two chemically active tracers produced chemically in the middle atmosphere (carbon monoxide and odd nitrogen) will now be discussed. The presence of carbon monoxide results from the oxidation of methane in the stratosphere and the photodissociation of carbon dioxide in the upper mesosphere. The corresponding production rate of $\mathrm{CO}$ is shown in Figure $8 a$. The two maxima associated with these two processes are visible: the first one associated with methane oxidation is located near $38-\mathbf{k m}$ altitude in the tropics, while the second one is found near $80 \mathrm{~km}$ in the summer hemisphere. The meridional distribution of $\mathrm{CO}$, resulting from these productions, the destruction of $\mathrm{CO}$ by the

Fig. 8. Meridional distribution (June conditions) of (a) the zonally averaged production rate, expressed in molecules per cubic centimeter per second, and $(b)$ the mixing ratio of carbon monoxide. The mixing ratio is represented by its decimal logarithm (e.g., -6 corresponds to 1 ppmv). Contour intervals: $600 \mathrm{~cm}^{-3}$ $\mathrm{s}^{-1}$ (Figure $8 x$ ) and 0.2 for Figure $8 b$.

of $\mathrm{H}_{2} \mathrm{O}$ on relatively small scales) or, less probably, the $\mathrm{OH}$ radical and the meridional transport, is shown in Figure $8 b$. The mixing ratio tends to decrease with height in the lower stratosphere and to increase with altitude above roughly $30-$ to $40-\mathrm{km}$ altitude. The chemical lifetime of carbon monoxide is of the order of 23 years near the tropopause and decreases with height to reach about 20 days in the mesosphere. Thus in most regions of the middle atmosphere, the chemical lifetime of $\mathrm{CO}$ is not significantly different from the dynamical characteristic time constant, so that carbon monoxide is an interesting tracer to study the role of atmospheric transport. Furthermore, the distribution of this constituent should be sensitive to chemical eddies. This effect is not yet included in the model.

The relatively abrupt variation in the concentration of $\mathrm{CO}$ at the edge of the polar vortex in winter is an indication that the strong downward flow at high latitude in the polar night transports substantial amounts of CO from the mesosphere (and ultimately from the thermosphere) down to the 40-km altitude region. Inside the mesospheric vortex the mixing ratio of $\mathrm{CO}$ is a factor of 5 larger than that at mid-latitudes. The interpretation of the $\mathrm{CO}$ measurements requires a multidimensional analysis which takes into account the sporadic fluctuations of dynamical conditions with consequences on the vertical transport of carbon monoxide and water vapor.

The production of odd nitrogen $\left(\mathrm{NO}_{y}\right)$, whose distribution in the meridional plane is shown in Figure 9a, results primarily from the oxidation of nitrous oxide, with 

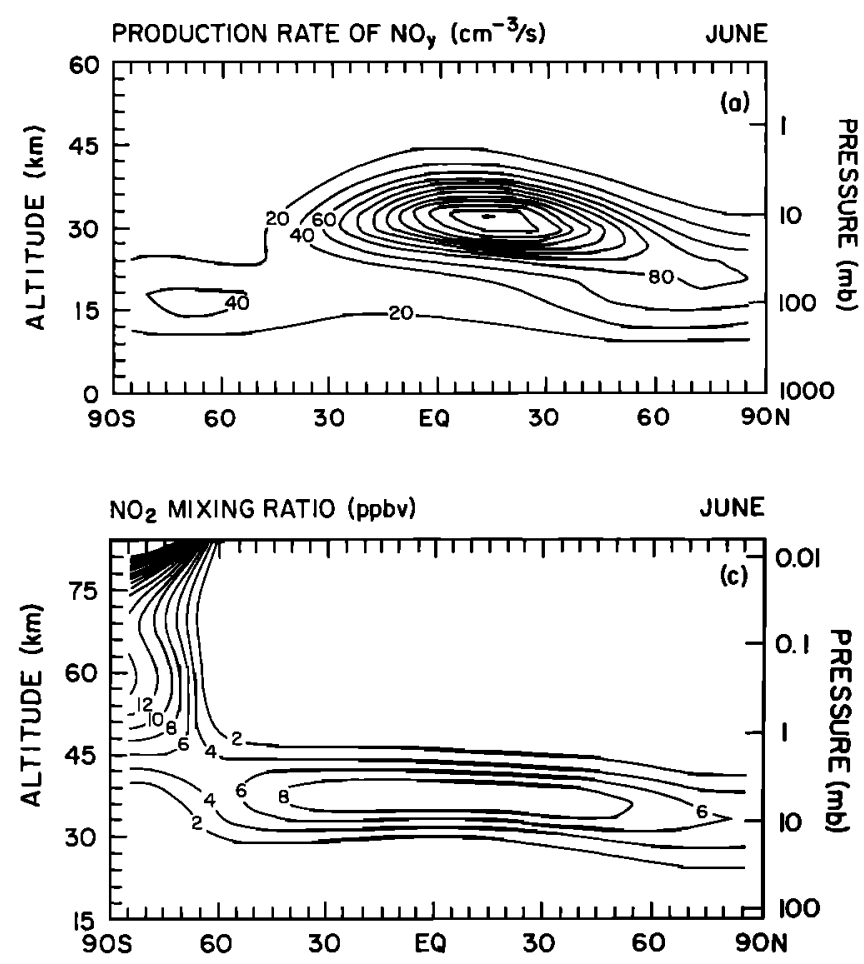
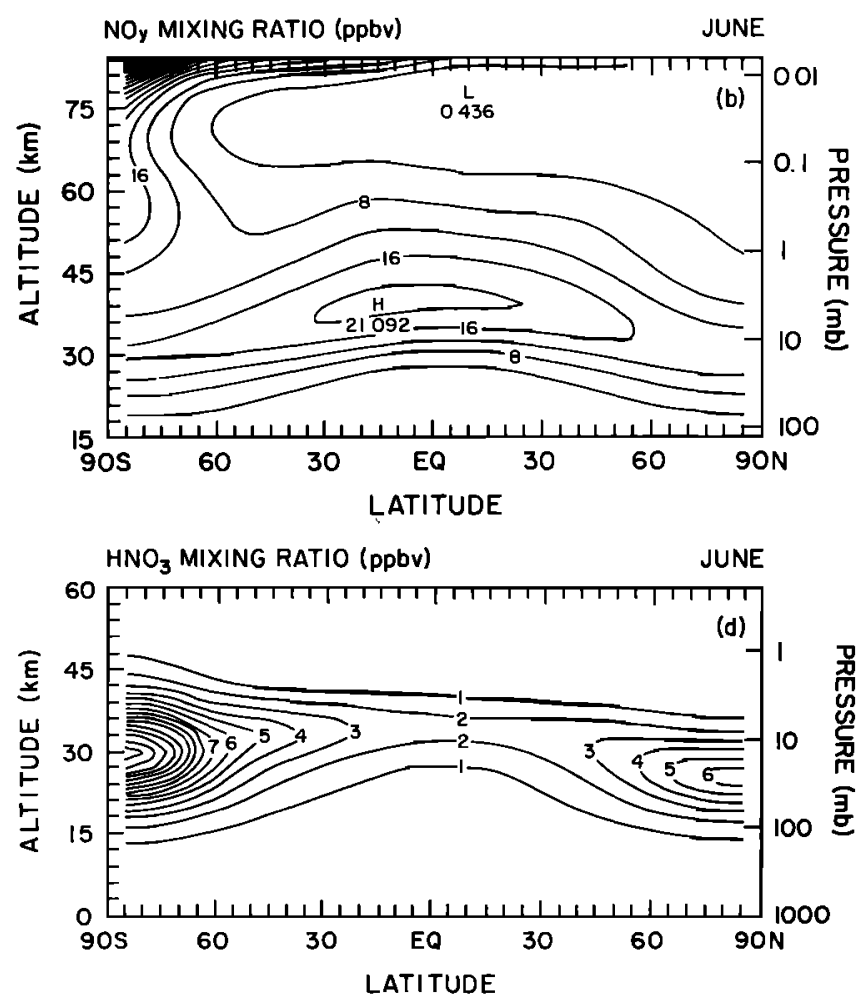

Fig. 9. Meridional distribution (June conditions) of the zonally averaged (a) production rate of odd nitrogen (expressed in molecules per cubic centimeter per second), $(b)$ mixing ratio of $\mathrm{NO}_{y}$ (expressed in parts per billion by volume), (c) 24-hour averaged mixing ratio of $\mathrm{NO}_{2}$, and (d) mixing ratio of $\mathrm{HNO}_{3}$. Contour intervals: $20 \mathrm{~cm}^{-3}$ $\mathrm{s}^{-1}$ (Figure 9a), 4 ppbv (Figure 9b), 2 ppbv (Figure 9c), and 1 ppbv (Figure 9d).

a maximum effect at $30 \mathrm{~km}$ altitude over the tropics. The contribution of the precipitation of cosmic rays (parameterized according to Nicolet [1975]) is apparent in the lower stratosphere, mainly at high latitudes. The net destruction of odd nitrogen occurs in the mesosphere through the predissociation of NO followed by the recombination of $\mathrm{N}$ and $\mathrm{NO}$, and in the troposphere through rapid rainout of nitric acid. The meridional distribution of $\mathrm{NO}_{y}$ resulting from these different processes is shown in Figure $9 b$ for June conditions. The calculated mixing ratio reaches a maximum of about 20 ppbv near $35-\mathrm{km}$ altitude over the tropics and a minimum of less than 0.5 ppbv near $75 \mathrm{~km}$ in the summer hemisphere. In the polar night the strong downward flow transports odd nitrogen from the thermosphere to the upper stratosphere. In the present model, which extends only up to the mesopause, the strength of the downward intrusion in the stratosphere of $\mathrm{NO}_{y}$ depends on the value of the boundary condition specified at $85 \mathrm{~km}$ (which should be variable in time, for example, as a function of season and solar activity).

The partitioning between the different elements of the odd nitrogen family depends on the solar elevation and hence varies with latitude, season, and time of day. The distribution of $\mathrm{NO}_{2}$ shown in Figure $9 c$ corresponds to a 24-hour averaged solar illumination. A maximum mixing ratio of nearly $10 \mathrm{ppbv}$ is obtained near 35km altitude, while a continuous increase with height of the mixing ratio is predicted in the region of the winter pole. In the case of nitric acid (Figure 9d), small diurnal variations are expected, especially in the lower stratosphere, because of the relatively long chemical lifetime of this molecule. A maximum mixing ratio is produced by the model over each pole, the largest value being found in winter. The highest concentration of more than $10 \mathrm{ppbv}$, calculated over the winter pole, results from a chemical conversion of $\mathrm{N}_{2} \mathrm{O}_{5}$ to $\mathrm{HNO}_{3}$ introduced in the model during the polar night with a time constant of 20 days. Experimental evidence for this type of conversion has been reported [Evans et al., 1985] and attributed to heterogeneous processes in the presence of polar clouds. The calculated mixing ratio of $\mathrm{HNO}_{3}$ reaches a maximum of $6.5 \mathrm{ppbv}$ over the summer pole and of $2.5 \mathrm{ppbv}$ over the equator.

The model also derives the meridional distribution of chlorine compounds. With chlorofluorocarbons $\mathrm{CH}_{3} \mathrm{Cl}$ and $\mathrm{CCl}_{4}$ corresponding nearly to the present-day abundances, the mixing ratio of odd chlorine $\left(\mathrm{Cl}_{x}\right)$ reaches a value of $2.9 \mathrm{ppbv}$ in the upper stratosphere and mesosphere. The 24-hour-averaged distributions of the two major chlorine reservoirs $\left(\mathrm{ClONO}_{2}\right.$ and $\left.\mathrm{HCl}\right)$ are represented in Figures $10 a$ and 10b. In the case of $\mathrm{ClONO}_{2}$ a maximum mixing ratio of about $1.4 \mathrm{ppbv}$ is found near $30 \mathrm{~km}$ altitude. In the case of $\mathrm{HCl}$ the mixing ratio in the stratosphere increases rapidly with altitude, particularly over the tropics, but its meridional gradient reverses above $35 \mathrm{~km}$, as a result of $\mathrm{HCl}-\mathrm{ClO}$ coupling, which becomes important in the upper stratosphere. The ratio of the $\mathrm{HCl}$ to $\mathrm{ClO}$ densities is proportional to the concentration of methane, which, at a given height, decreases as a function of latitude. As seen in Figure 10c, the mixing ratio of ClO peaks near $45-\mathrm{km}$ altitude, the largest values being found at high latitudes. 

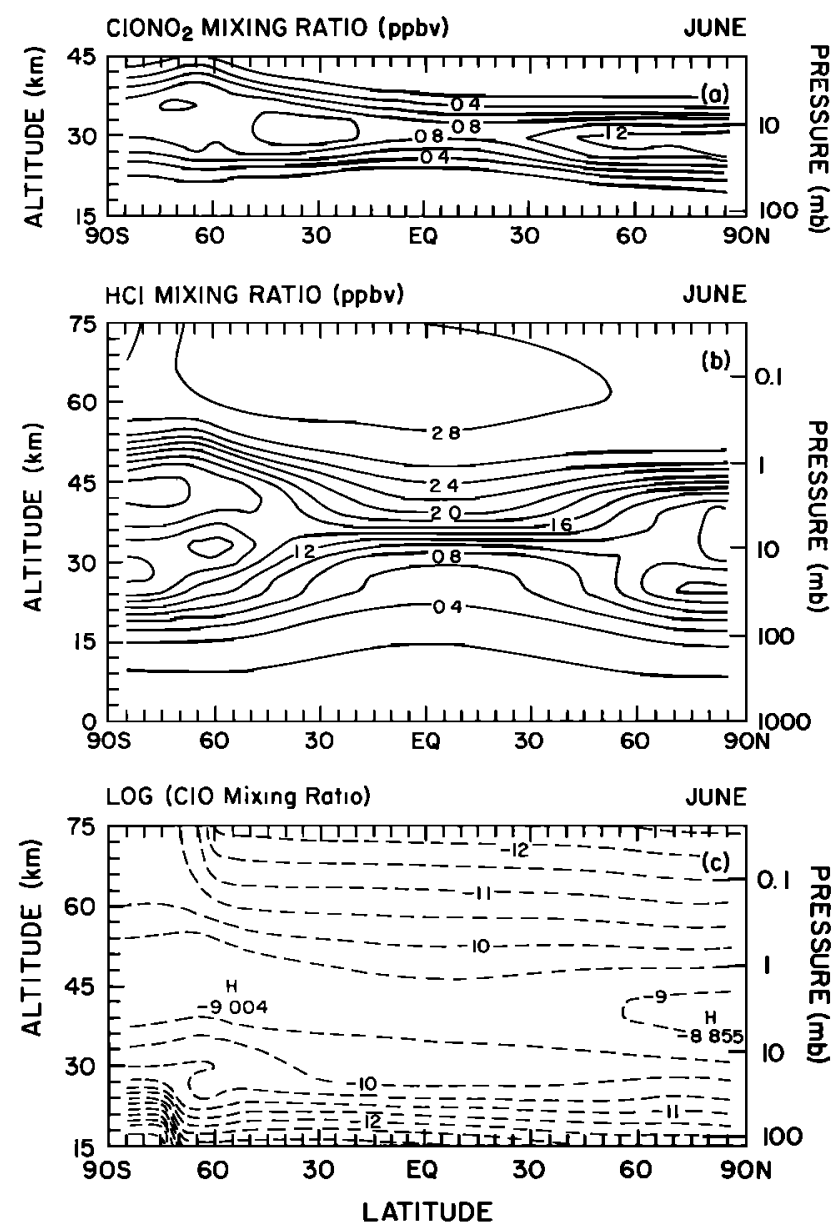

Fig. 10. Meridional distribution (June conditions) of the zonally averaged and 24-hour-averaged mixing ratio of (a) $\mathrm{ClONO}_{2}$ (expressed in parts per billion by volume), (b) $\mathrm{HCl}$ (expressed in parts per billion by volume), and (c) ClO (expressed by the decimal logarithm of its value). Contour intervals: $0.2 \mathrm{ppbv}$ (Figures $10 a$ and $10 b$ ) and 0.5 (Figure 10c).

The formation of odd oxygen in the middle atmosphere results from the photolysis of molecular oxygen and its destruction from recombination processes which are catalyzed by the presence of radicals belonging to the hydrogen, nitrogen, and chlorine families (see, for example, Brasseur and Solomon [1986]). The study of the ozone budget requires an accurate determination of the densities of these radicals (see above). Since the photochemical lifetime of odd oxygen is highly variable with altitude and latitude, different regimes have to be distinguished. In the upper stratosphere and in the mesosphere, where the chemical time constant for $\mathrm{O}_{x}$ is of the order of a day or less, photochemical equilibrium conditions are applicable in the sunlit atmosphere, and the density of $\mathrm{O}, \mathrm{O}_{3}$ (and $O_{x}$ ) exhibits diurnal variations. The lifetime of odd oxygen increases toward lower altitudes and reaches a value of several years at the tropopause. In these regions, $\mathrm{O}_{\boldsymbol{x}}$ and ozone are quasi-conservative tracers.

The calculated distributions of odd oxygen (primarily ozone in the stratosphere) for solstice and equinox are shown in Figures $11 a$ and $11 b$. The observed climatologies, established primarily from satellite measurements (e.g., solar backscatter ultraviolet (SBUV) and LIMS on Nimbus 7), and the model results show similar patterns: the mix-
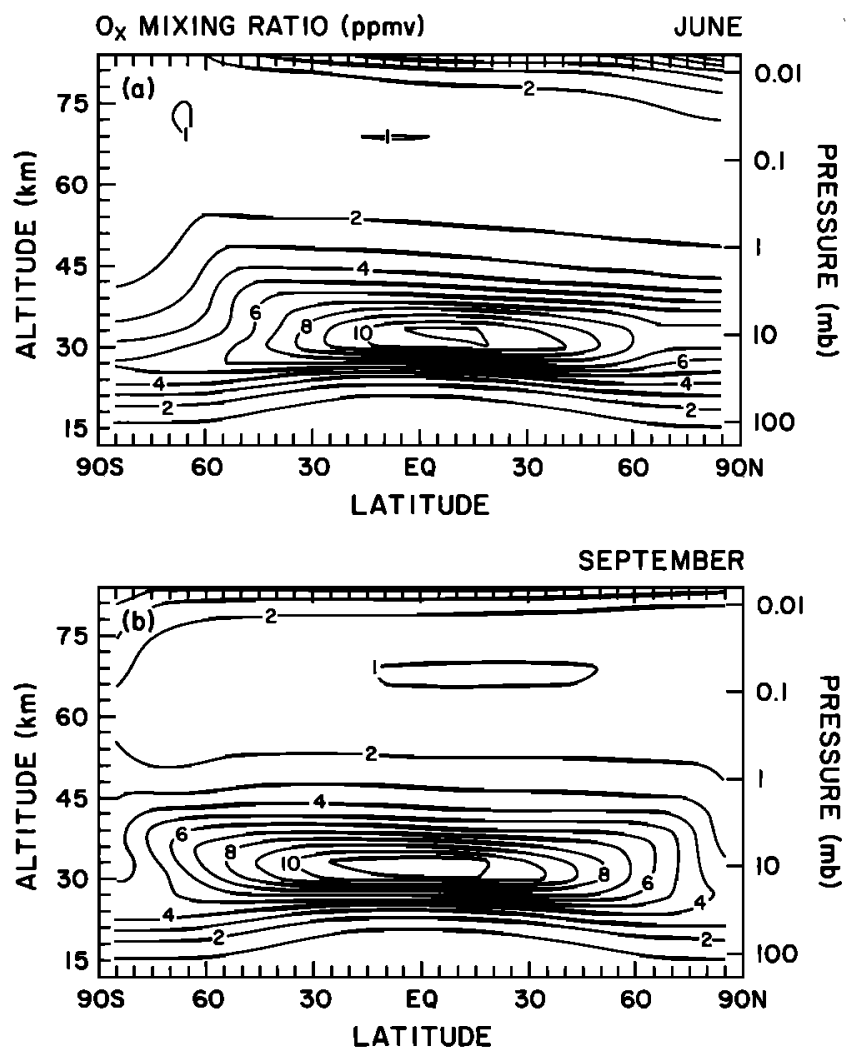

Fig. 11. Meridional distribution of the zonally averaged mixing ratio of odd oxygen in (a) June and (b) September, expressed in parts per million by volume. Contour intervals: 1 ppmv.

ing ratio peaks over the tropics near $30-\mathbf{k m}$ altitude, but the calculated mixing ratio is perhaps $10 \%$ higher than the observed value. The slopes of isolines in the lower stratosphere are similar in the model and in the data. The model however underestimates by about $20-30 \%$ the ozone density in the upper stratosphere, a feature which is common to many models [Froidevaux et al., 1985] and needs to be clarified. Perhaps the most visible discrepancy between the calculated and the observed ozone appears in

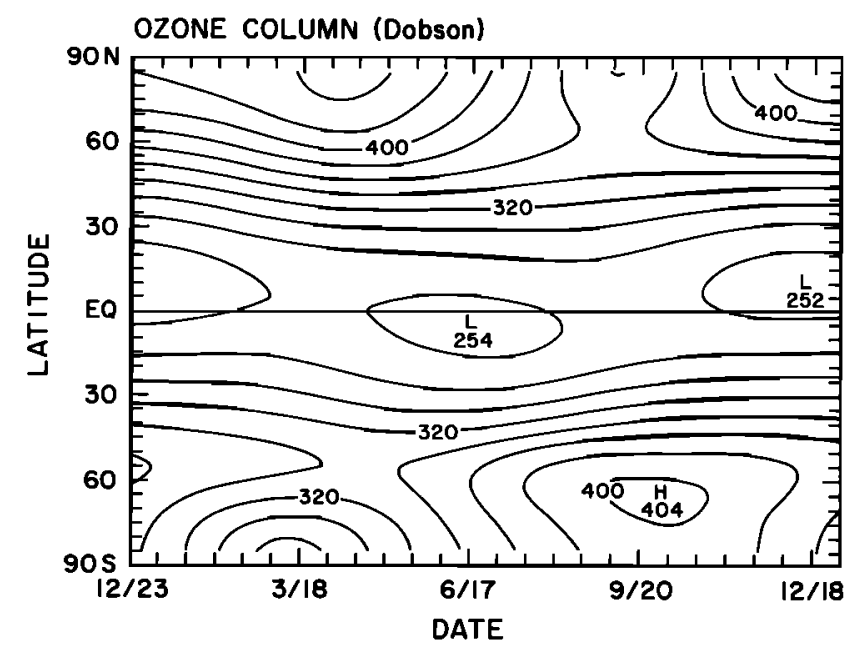

Fig. 12. Ozone column abundance represented as a function of latitude and season and expressed in Dobson units (300 DU corresponds to an ozone layer of $0.3 \mathrm{~cm}$ at standard pressure and temperature). Contour intervals: $20 \mathrm{DU}$. 
the region of the polar night. In this part of the atmosphere, where no solar radiation is available, the density of ozone is governed exclusively by the mean circulation and by eddy mixing. A too strong downward flow at the winter pole in the upper stratosphere is probably responsible for the low mixing ratio derived in the polar night above $40-\mathrm{km}$ altitude. The high ozone concentrations calculated at high latitude below $30 \mathrm{~km}$ during the same season are more typical of a dynamically disturbed situation (sudden stratospheric warming) than of a climatological average distribution and are probably associated with too large values of the eddy mixing derived from the planetary wave formulation. This problem will be addressed when a detailed parameterization of the chemical eddies will be introduced in the model.

One of the most stringent tests for validating the representation of transport processes in the lower stratosphere
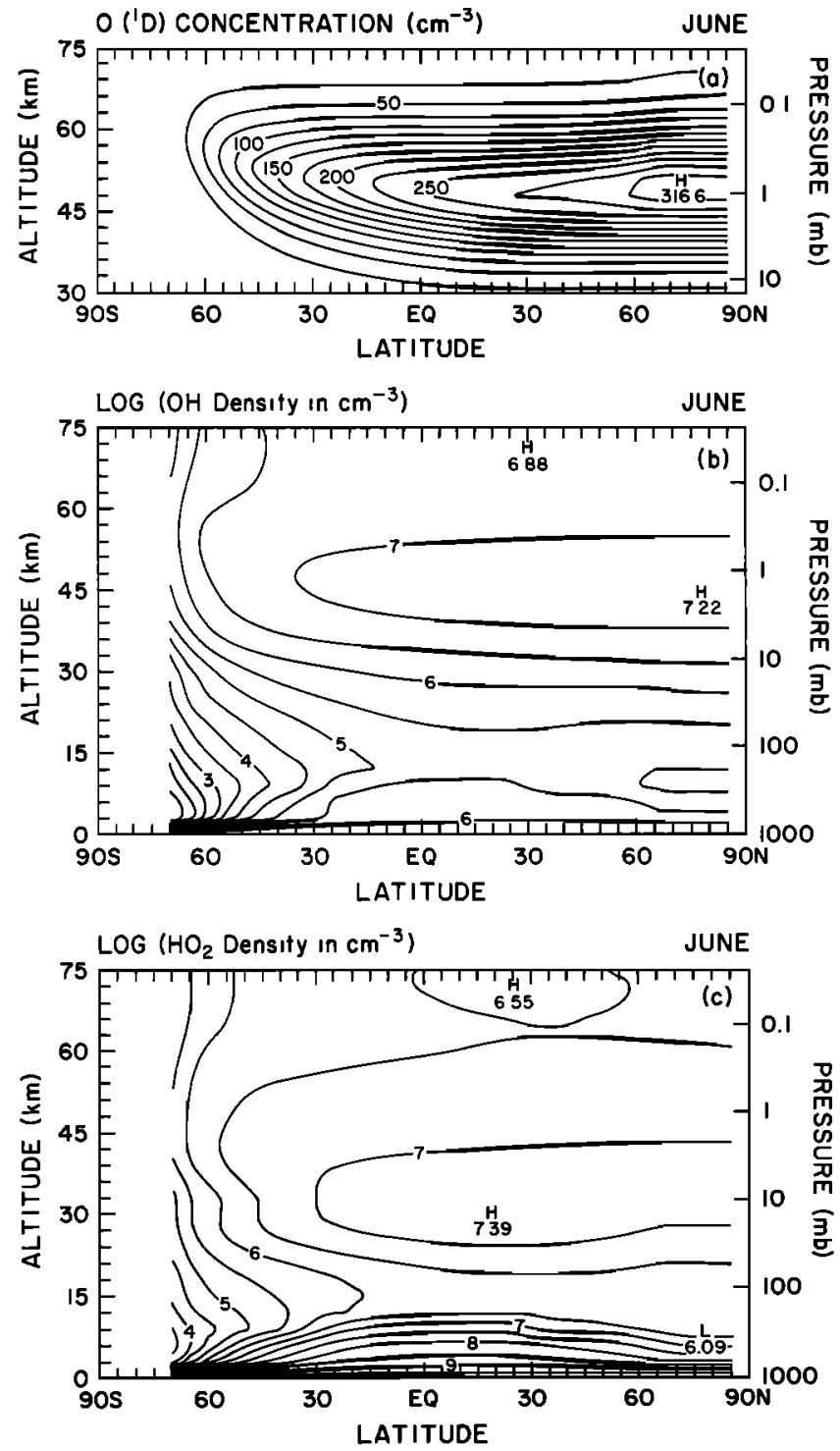

Fig. 13. Meridional distribution of the 24-hour-averaged number density of $(a) O\left({ }^{1} \mathrm{D}\right),(b) \mathrm{OH}$, and (c) $\mathrm{HO}_{2}$. The densities are expressed in molecules per cubic centimeter per second. In Figures $13 b$ and $13 c$ the concentrations are represented by the decimal logarithms of their values. Contour intervals: $25 \mathrm{~cm}^{-3}$ (Figure 13a), 0.5 (Figures $13 b$ and 13c). is provided by the ability of the model to reproduce the observed latitude-season variation of total ozone (Dobson map). A comparison of the calculated (Figure 12) and climatological Dobson map shows that the model reproduces successfully the low ozone column abundance in the equatorial region as well as its increase with latitude, which is most pronounced in winter and early spring. The hemispheric difference is also well represented by the model. This result, however, strongly depends on the assumed vertical wind velocity at $15-\mathrm{km}$ altitude. A maximum value of 440 Dobson units is calculated over the north pole in March. In the southern hemisphere a maximum of 404 Dobson units is found in September at $60^{\circ} \mathrm{S}$. Perhaps the largest discrepancy with observations is that ozone column abundances in fall over the pole, particularly in the northern hemisphere, are too large on account of the slow removal of ozone at high latitude during the summer. It is interesting to note that although no heterogeneous process is included in the chemical scheme of the model (such processes are thought to produce the "ozone hole" observed in spring since the early 1970s), a slight ozone minimum is predicted by the model over the south pole in September. The morphology of the ozone column abundance derived by the model is thus representative of the "pre-ozone hole" period.

To complete this discussion of the chemical composition calculated by the model for present-day conditions, Figures $13 a, 13 b$, and $13 c$ present the meridional distributions of three fast-reacting species of significant importance in the middle atmosphere. $\mathrm{O}\left({ }^{1} \mathrm{D}\right), \mathrm{OH}$, and $\mathrm{HO}_{2}$. The 24hour averaged number density of the electronically excited oxygen atom calculated for June conditions reaches a maximum of about $300 \mathrm{~cm}^{-3}$ in the upper stratosphere over the summer pole. In the case of the hydroxyl radical, the maximum 24-hour-averaged concentration is found near $45 \mathrm{~km}$ in the summer case, while, in the case of peroxy radicals, the maximum density is located near $30-\mathrm{km}$ altitude over the tropics. The $\mathrm{HO}_{2} / \mathrm{OH}$ concentration ratio is of the order of 0.8 in the upper stratosphere, but it increases with decreasing altitude and reaches about 10 at the tropopause and $\mathbf{1 0 0 0}$ in the lower troposphere.

\section{Responses of the Middle Atmosphere to Perturbations by Trace Gases}

It is now well recognized that the release in the atmosphere of chemically and radiatively active trace gases, resulting from human activities, should modify the composition and the temperature of the atmosphere and consequently produce significant changes in the general circulation and in the climate of the Earth. A comprehensive study of the possible modifications expected to occur in the climate system requires a detailed simulation of numerous interactive processes between the atmosphere and other parts of the geosphere, such as the ocean, the biosphere, the cryosphere, and the technosphere. Our purpose in this section is not to conduct such a study but to simply determine how the model responds to prescribed changes in the abundance of two gases whose concentration is known to be increasing with time.

Carbon dioxide, whose density is expected to double before the middle of the twenty-first century, is chemically inert but radiatively active, especially through a strong band in the infrared at $15 \mu \mathrm{m}$. The presence of this gas greatly affects the temperature of the atmosphere 
and consequently the chemical rate constants and hence the atmospheric composition. By absorbing, and reemitting, infrared radiation, carbon dioxide contributes to the greenhouse effect of the atmosphere. This aspect of the problem will not be considered in the present study, as the temperature in the troposphere, as well as its changes for perturbed conditions, are specified rather than calculated in the present version of the model.

Figures 14a, 14b, and $14 c$ show for June conditions the response of the model for a doubling of $\mathrm{CO}_{2}$. As expected, the temperature decreases above about $20 \mathrm{~km}$ (Figure 14a). The strongest cooling is found near the stratopause $(8 \mathrm{~K}$ at the equator, $10 \mathrm{~K}$ at the summer pole, and $17 \mathrm{~K}$ at the winter pole). A slight heating
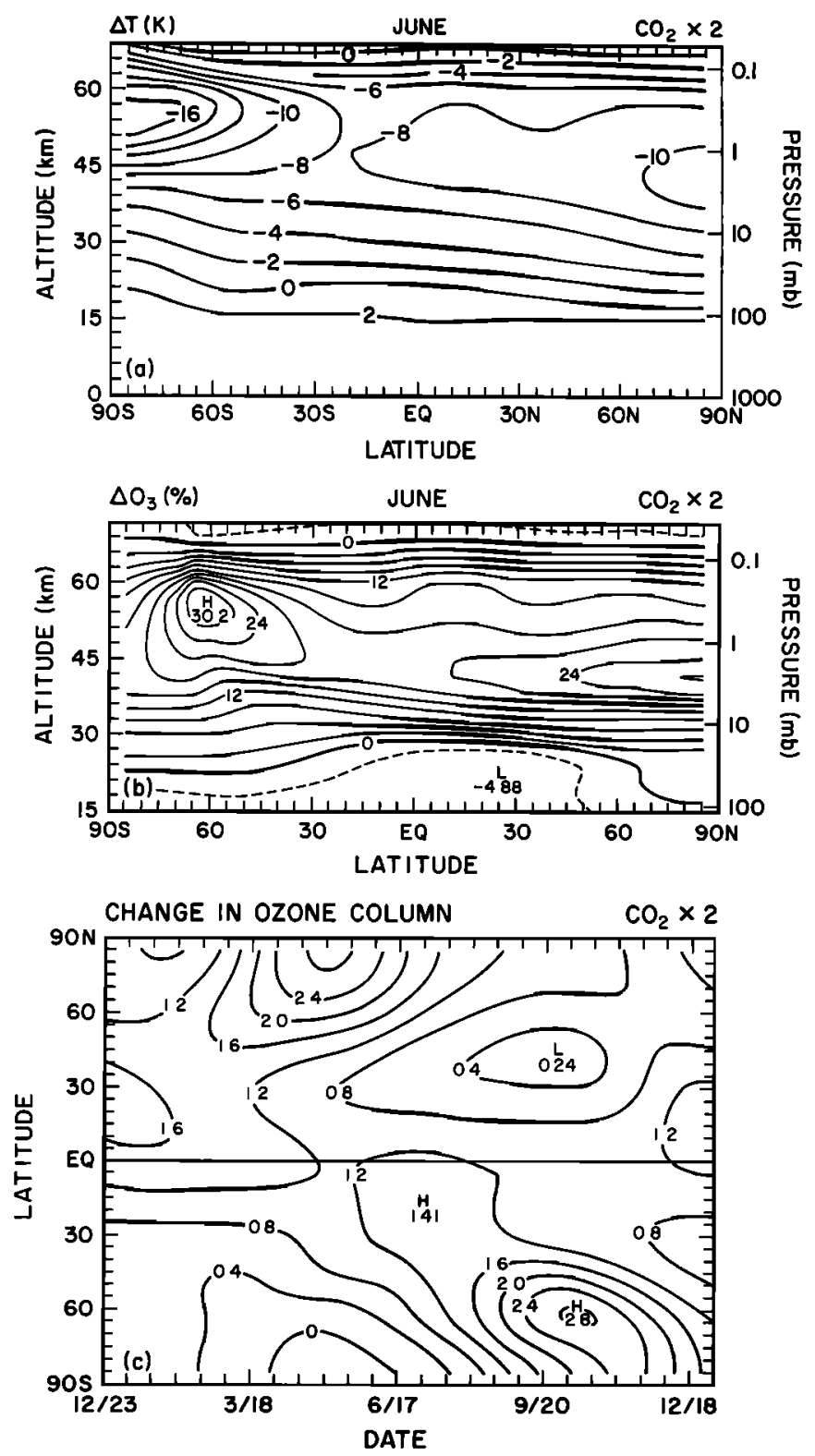

Fig. 14. Response of the atmosphere to a doubling in carbon dioxide in June: (a) change in temperature (expressed in Kelvins), (b) change in the ozone density (expressed in percent) in June, and (c) change in the ozone column abundance as a function of latitude and season (expressed in percent). Contour intervals: 2 $\mathrm{K}$ (Figure 14a), 3\% (Figure 14b), and $0.4 \%$ (Figure 14c). appears in the lower stratosphere, up to about 20-km altitude. The consequence of the substantial cooling in the middle and upper stratosphere is a reduction in the ozone loss rate and consequently an increase in the ozone density with a relative maximum near $45 \mathrm{~km}$ (20\% at the equator, $27 \%$ at the summer pole, $30 \%$ near the terminator). The result of these enhanced ozone abundances in the upper stratosphere is a stronger absorption of solar ultraviolet radiation in the vicinity of the stratopause and consequently a weaker production of ozone in the lower stratosphere, where a reduced ozone density is predicted by the model. The "zero line" in the ozone change is located at the very height where the density of $\mathrm{O}_{3}$ reaches its maximum. Hence as shown by Figure 14c, the increase in the ozone is limited to 0.5 to $2.8 \%$, depending on latitude and season. The largest increase is found at high latitude at the end of the winter, when strong downward motions transport ozone-enriched air from the upper stratosphere to lower altitudes.

Similar changes in temperature and ozone are shown in Figures $15 a, 15 b$, and $15 c$ for an increase in the abundance of the chlorofluorocarbons. These gases of industrial origin have a atmospheric lifetime of several decades, and their concentration is known to increase by about $5 \%$ per year. In the simulation presented here, the mixing ratio of odd chlorine in the upper stratosphere is increasing from $2.9 \mathrm{ppbv}$ to $8.5 \mathrm{ppbv}$. This perturbation corresponds roughly to a change from present conditions to a situation expected to occur in the middle of the twenty-first century if the release in the atmosphere of chlorofluorocarbons does not exceed the emissions authorized by the recent protocol on the protection of the ozone layer (Montreal, September 1987). The depletion in the ozone density at $45-\mathrm{km}$ altitude reaches $32 \%$ at the equator and $50 \%$ at high latitude. This latitudinal dependence arises from the decrease with latitude of the methane density and consequently a slower conversion of active chlorine radicals to inactive chlorine reservoirs as one gets closer to the poles. As a result of deeper penetration of solar radiation, a small ozone increase (about $5 \%$ ) is found in the lower stratosphere over the tropics. The reduction in the ozone column abundance determined for this scenario is of the order of $2 \%$ near the equator and increases with latitude in winter and spring. During this time of the year, the ozone is depleted by as much as $6 \%$ at high latitude. It should be emphasized that these changes do not account for the effects of heterogeneous chemistry and that they should therefore be considered as lower limits.

The change in the temperature determined by the model is a direct consequence of the large reductions in the densities of stratospheric ozone. The direct radiative effect of the chlorofluorocarbons is neglected in this calculation as it is known to be significantly lower than the indirect effect on the temperature associated with ozone reductions. The largest cooling takes place at $45 \mathrm{~km}$ at the summer pole $(13 \mathrm{~K}$ ) (see Figure 15a). In the winter hemisphere, especially in the polar night where the contribution of ozone to the value of the temperature is small, the perturbation in the temperature is weaker.

Finally, when carbon dioxide and the chlorofluorocarbons are perturbed simultaneously, the decrease in temperature are almost additive $(23 \mathrm{~K}$ at $45 \mathrm{~km}$ near the summer pole), and the changes in the ozone density are 

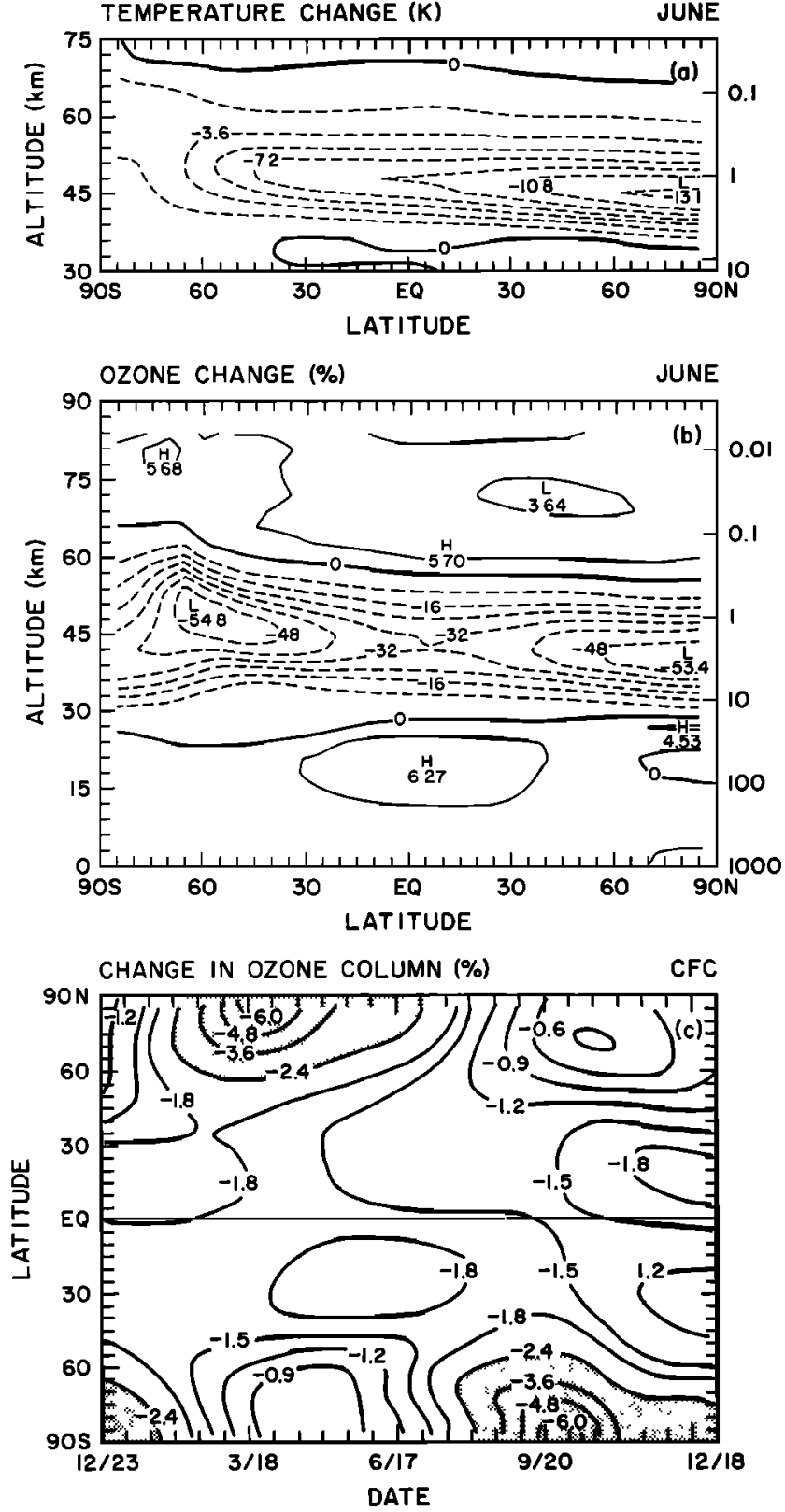

Fig. 15. Same as in Figure 14 but for an increase in active chlorine from $2.9 \mathrm{ppbv}$ to $8.5 \mathrm{ppbv}$. Contour intervals: $1.8 \mathrm{~K}$ (Figure $15 a), 8 \%$ (Figure $15 b)$, and $03 \%(1.2 \%$ in the shaded zones) (Figure 15c).

intermediate between the two previous cases (reduction of $20 \%$ at the equator and $40 \%$ at the poles at $45 \mathrm{~km}$ ). An increase of $20 \%$ is found at $60 \mathrm{~km}$ in the summer hemisphere, since at this height the effect of $\mathrm{CO}_{2}$ is substantially larger than that of the chlorofluorocarbons.

\section{Concluding Remarks and Future Work}

The purpose of this paper was to present a full description of an interactive chemical-dynamical-radiative model of the middle atmosphere and to discuss selected results obtained for the present atmosphere and for perturbed conditions. The calculated distributions of the trace gases are generally consistent with observations available on a global scale. Some discrepancies, which have been indicated in the previous discussion, need to be understood and resolved. A major problem that needs to be elucidated is the underestimation by most models of the ozone density in the upper stratosphere, where ozone is highly sensitive to the local temperature. The effect of tropical dynamics needs also to be studied more carefully and the exchanges between the troposphere and the stratosphere need further consideration.

An elaborate parameterization of the absorption of Rossby waves and its impact on momentum deposition and large-scale mixing has recently been implemented in the model [Hitchman and Brasseur, 1988]. The model has also been used to study the response of the atmosphere during the 1980s to increased emissions of trace gases of human origin and to changes in solar activity [Brasseur et al., 1988b].

We intend in the near future to study the role of chemical eddies in the transport of species, to introduce the effects of Kelvin waves in the tropics, to include additional chemical mechanisms such as heterogeneous processes on the surface of ice particles in the polar stratospheric clouds or of aerosol particles at all latitudes, and especially for climate studies, to extend our dynamical scheme in to the troposphere and to couple this model to a surface ocean-land model. The results from these different projects will be reported in forthcoming papers.

\section{Appendix: Numerical Resolution of the Continuity-Transport Equation}

If the source term $S$ is expressed as

$$
S=P-L X
$$

where $X$ is the mixing ratio of a trace constituent, $P$ is its chemical production rate, and $L$ is its loss coefficient, the continuity-transport equation (20) can be rewritten as

$$
\frac{\partial X}{\partial t}+A \frac{\partial^{2} X}{\partial y^{2}}+B \frac{\partial^{2} X}{\partial z^{2}}+C \frac{\partial X}{\partial y}+D \frac{\partial X}{\partial z}+E X=F
$$

where

$$
\begin{aligned}
& A \equiv-K_{y y} \\
& B \equiv-K_{z z} \\
& C \equiv \overline{v^{*}}-\frac{\partial K_{y y}}{\partial y}+K_{y y} \frac{\tan \phi}{a} \\
& D \equiv \overline{w *}-\frac{\partial K_{z z}}{\partial z}+\frac{K_{y z}}{H *} \\
& E \equiv L \\
& F \equiv P
\end{aligned}
$$

(See the notation section for definition of the symbols.) This equation is solved by the alternating-direction implicit method [Peaceman and Rachford, 1955]. The idea of this time-splitting algorithm is to divide each time step into two steps of size $\Delta t / 2$. In each substep a different dimension is treated implicitly. Using a time-forward, space-centered differencing scheme, the equation can be approximated at each grid point $(i, j)$ and at time $n$ by

$$
\begin{gathered}
\beta_{i, j}^{n} X_{i-1, j}^{n+1 / 2}+\alpha_{i, j}^{n} X_{i, j}^{n+1 / 2}+\gamma_{i, j}^{n} X_{i+1, j}^{n+1 / 2}= \\
\Psi_{i, j}^{n}-\delta_{i, j}^{n} X_{i, j-1}^{n}-\phi_{i, j}^{n} X_{i, j}^{n}-\epsilon_{i, j}^{n} X_{i, j+1}^{n} \\
\delta_{i, j}^{n} X_{i, j-1}^{n+1}+\tilde{\alpha}_{i, j} X_{i, j}^{n+1}+\epsilon_{i, j} X_{i, j+1}^{n+1}= \\
\Psi_{i, j}^{n}-\beta_{i, j}^{n} X_{i-1, j}^{n+1 / 2}-\tilde{\phi}_{i, j}^{n} X_{i, j}^{n+1 / 2}-\gamma_{i, j}^{n} X_{i+1, j}^{n+1 / 2}
\end{gathered}
$$


where

$$
\begin{aligned}
& \alpha=1-\frac{A \Delta t}{\Delta y^{2}}+\frac{E \Delta t}{2} \\
& \tilde{\alpha}=1-\frac{B \Delta t}{\Delta z^{2}}+\frac{E \Delta t}{2} \\
& \beta=\frac{A \Delta t}{2 \Delta y^{2}}-\frac{C \Delta t}{4 \Delta y} \\
& \gamma=\frac{A \Delta t}{2 \Delta y^{2}}+\frac{C \Delta t}{4 \Delta y} \\
& \delta=\frac{B \Delta t}{2 \Delta z^{2}}-\frac{D \Delta t}{4 \Delta z} \\
& \epsilon=\frac{B \Delta t}{2 \Delta z^{2}}+\frac{D \Delta t}{4 \Delta y} \\
& \phi=-1-\frac{B \Delta t}{\Delta z^{2}} \\
& \tilde{\phi}=-1-\frac{A \Delta t}{\Delta y^{2}} \\
& \Psi=\frac{F \Delta t}{2}
\end{aligned}
$$

The two systems involve tridiagonal matrices and can therefore easily be solved by a standard tridiagonal algorithm. This alternating-direction method is first-order accurate in time and second-order accurate in space, unconditionally stable, and therefore suitable for the integration of the model over long periods of time without prohibitive computer costs.

\section{Notation}

$\overline{()},()^{\prime}$ Eulerian zonal mean and deviation.

$A$ Rossby wave activity.

$a$ radius of the Earth.

$B$ amplitude factor for gravity wave driving.

$C_{F}$ forcing term in stream function equation.

$c$ zonal trace speed.

$E_{y}, E_{z}$ components of the Eliassen-Palm flux.

$F_{R}, F_{g}$ body force per unit mass due to Rossby and gravity waves.

$D_{\theta}$ flux convergence terms for entropy equation.

$f$ Coriolis parameter.

$G_{y}, G_{z}$ meridional and vertical group speeds.

g gravitational acceleration.

$H$ scale height.

$K_{y y}, K_{z z}$ meridional and vertical eddy mixing coefficients.

$N$ buoyancy frequency.

$Q$ heating rate for potential temperature.

$q$ basic state potential vorticity.

$S$ source term.

$T$ temperature.

$u, v, w$ zonal, meridional and vertical wind components.

$\tilde{u}$ amplitude factor for determining $z_{b}$.

$\bar{v}^{*}, \bar{w}^{*}$ Eulerian mean residual circulation.

$z_{b}, z_{c}$ breaking altitude and critical level.

$\alpha$ damping rate.

$\gamma$ modified Coriolis parameter.

$\eta$ absolute vorticity.

$\theta$ potential temperature.

$\mu$ tracer mixing ratio.

$\rho_{o}$ basic state density.

$\phi$ latitude.

$\chi$ residual mean meridional velocity stream function.

$\psi$ residual mean meridional mass stream function.
Acknowledgments. Comments on this manuscript by Ralph J. Cicerone, William J. Randel, and Anne K. Smith are gratefully acknowledged. The authors are also grateful for helpful discussions with J. C. Gille and L. V. Lyjak. This work was supported in part by the Commission of the European Communities under contract CLi 107-B(RS), and by the National Aeronautics and Space Administration through grant $W$ 16215. The National Center for Atmospheric Research is sponsored by the National Science Foundation.

\section{REFERENCES}

Andrews, D. G., and M. E. McIntyre, Planetary waves in horizontal and vertical shear: The generalized Eliassen-Palm relation and the mean zonal acceleration, J. Atmos. Sci., 93, 2031-2048, 1976.

Andrews, D. G., J. R. Holton, and C. B. Leovy, Middle Atmosphere Dynamics, 489 pp., Academic, San Diego, Calif., 1987.

Bevilacqua, R. M., W. J. Wilson, W. B. Ricketts, P. R. Schwartz, and R. J. Howard, Possible seasonal variability of mesospheric water vapor, Geophys. Res. Lett., 12, 397-400, 1985.

Boyd, J. P., The noninteraction of waves with the zonally averaged flow on a spherical Earth and the interrelationships of eddy fluxes of energy, heat and momentum, J. Atmos. Sci., $39,2285-2291,1976$.

Brasseur, G., and M. H. Hitchman, The effect of breaking gravity waves on the distribution of trace species in the middle atmosphere, in Transport Processes in the Middle Atmosphere, edited by G. Visconti and R. Garcia, pp. 215-227, D. Reidel, Hingham, Mass., 1987.

Brasseur, G., and P. C. Simon, Stratospheric chemical and thermal response to long-term variability in solar UV irradiance, J. Geophys. Res., 86, 7343-7362, 1981.

Brasseur, G., and S. Solomon, Aeronomy of the Middle Atmosphere: Chemistry and Physics in the Stratosphere and Mesosphere, 452 pp., D. Reidel, Hingham, Mass., 1986.

Brasseur, G., et al., Group report on "Changes in Antarctic Ozone", in The Changing Atmosphere, edited by F. S. Rowland and I. S. A. Isaksen, Pp. 235-256, John Wiley, New York, 1988a.

Brasseur, G., M. H. Hitchman, P. C. Simon, and A. DeRudder, Ozone reduction in the 1980's: A model simulation of anthropogenic and solar perturbations, Geophys. Res. Lett., $15,1361-1364,1988 b$.

Brewer, A. W., Evidence for a world circulation provided by the measurements of helium and water vapour distribution in the stratosphere, Q. J. R. Meteorol. Soc., 75, 351-363, 1949.

Cess, R. D., Climate change: An appraisal of atmospheric feedback mechanisms employing zonal climatology, J. Atmos. Sci., 39, 1831-1843, 1976.

DeMore, W. B., J. J. Margitan, M. J. Molina, R. T. Watson D. M. Golden, R. F. Hampson, M. J. Kurylo, C. J. Howard, and A. R. Ravishankara, Chemical kinetics and photochemical data for use in stratospheric modeling, Evaluation number 7, JPL Publ. 85-37, Jet Propul. Lab., Pasadena, Calif., 1985.

Dobson, G. M. B., Origin and distribution of polyatomic molecules in the atmosphere, Proc. R. Soc. London., Ser. A, 296, 187-193, 1956.

Dunkerton, T. J., On the mean meridional mass motions in the stratosphere and mesosphere, J. Atmos. Sci., 35, 2325$2333,1978$.

Edmon, H. J., Jr., B. J. Hoskins, and M. E. McIntyre, EliassenPalm cross sections for the troposphere, J. Atmos. Sci., 31, 2600-2616, 1980.

Evans, W. F. J., C. T. McElroy, and I. E. Galbally, The conversion of $\mathrm{N}_{2} \mathrm{O}_{5}$ to $\mathrm{HNO}_{3}$ at high latitudes in winter, Geophys. Res. Lett., 12, 825-828, 1985.

Farman, J. C., B. G. Gardiner, and J. D. Shanklin, Large losses of total ozone in Antarctica reveal seasonal $\mathrm{ClO}_{x} / \mathrm{NO}_{x}$ interaction, Nature, 315, 207-210, 1985.

Froidevaux, L., M. Allen, and Y. L. Yung, A critical analysis of $\mathrm{ClO}$ and $\mathrm{O}_{3}$ in the mid-latitude stratosphere, J. Geophys. Res., 90, 12,999-13,030, 1985.

Garcia, R. R., and S. Solomon, A numerical model of the zonally averaged dynamical and chemical structure of the middle atmosphere, J. Geophys. Res., 88, 1379-1400, 1983. 
Garcia, R. R., and S. Solomon, The effect of breaking gravity waves on the dynamical and chemical composition of the mesosphere and lower thermosphere, J. Geophys. Res., 90, 3850-3868, 1985.

Gray, L. J., and J. A. Pyle, Semi-annual oscillation and equatorial tracer distributions, Q. J. R. Meteorol. Soc., 112, 387-407, 1986.

Gudiksen, P. H., A. W. Fairhall, and R. J. Reed, Roles of mean meridional circulation and eddy diffusion in the transport of trace substances in the lower stratosphere, J. Geophys. Res., 79, 4461-4473, 1968.

Guthrie, P. D., C. H. Jackman, J. R. Herman, and C. J. McQuillan, A diabatic circulation experiment in a two-dimensional photochemical model, J. Geophys. Res., 89, 9589-9602, 1984.

Hitchman, M. H., and G. Brasseur, Rossby wave activity in a twodimensional model: Closure for wave driving and meridional eddy diffusivity, J. Geophys. Res., 93, 9405-9417, 1988.

Hitchman, M. H., and C. B. Leovy, Evolution of the zonal mean state in the equatorial middle atmosphere during October 1978-May 1979, J. Atmos. Sci., 43, 3159-3176, 1986.

Holton, J. R., An advective model for two-dimensional transport of stratospheric trace species, J. Geophys. Res., 86, 11,989$11,994,1981$

Holton, J. R., The role of gravity wave induced drag and diffusion in the momentum budget of the mesosphere, J. Atmos. Sci., 39, 791-799, 1982.

Jackman, C. H., P. A. Newman, P. D. Guthrie, and M. R. Schoeberl, Effect of computed horizontal diffusion coefficients on two-dimensional $\mathrm{N}_{2} \mathrm{O}$ model distributions, J. Geophys. Res., 93, 5213-5219, 1988.

Jones, R. L., and J. A. Pyle, Observations of $\mathrm{CH}_{4}$ and $\mathrm{N}_{2} \mathrm{O}$ by the Nimbus 7 SAMS: A comparison with in-situ data and two-dimensional numerical model calculations, J. Geophys. Res., 89, 5263-5279, 1984.

Kiehl, J. T., and T. Yamanouchi, A parameterization for absorption due to the A, B, and $\gamma$ oxygen bands, Tellus, Ser. B, $37,1-6,1985$.

Kiehl, J. T., R. J. Wolski, B. P. Briegleb, and V. Ramanathan, Documentation of radiation and cloud routines in the NCAR community climate model (CCM1), NCAR Tech. Note $N C A R / T N-288+I A$, Natl. Cent. for Atmos. Res., Boulder, Colo., 1987.

Kratz, D. P., and R. D. Cess, Solar absorption by atmospheric water vapor: A comparison of radiation models, Tellus, Ser. $B, 37,53-63,1985$.

Lacis, A. A., and J. E. Hansen, A parameterization for the absorption of solar radiation in the Earth's atmosphere, $J$. Atmos. Sci., 31, 118-133, 1974.

LeTexier, H., S. Solomon, and R. R. Garcia, The role of molecular hydrogen and methane oxidation in the water vapour budget of the stratosphere, Q. J. R. Meteorol. Soc., 114, 281-295, 1988.

Lindzen, R. S., Turbulence and stress owing to gravity wave and tidal breakdown, J. Geophys. Res., 86, 9707-9714, 1981

Mahlman, J. D., Some fundamental limitations of simplified transport models as implied by results from a threedimensional general circulation/tracer model, in Proceedings of the Fourth Conference of the Climatic Impact Assessment Program, edited by T. M. Hard and A. J. Broderick, Publ.
DOT-TSC-OST-75-38, pp. 132-146, Dept. of Transportation, Cambridge, Mass., 1975.

Matsuno, T., Lagrangian motion of air parcels in the stratosphere in the presence of planetary waves, Pure Appl. Geophys., $118,189-216,1980$.

Murgatroyd, R. J., and F. Singleton, Possible meridional circulations in the stratosphere and mesosphere, Q. J. R. Meteorol. Soc., 87, 125-135, 1961.

Nicolet, M., On the production of nitric oxide by cosmic rays in the mesosphere and stratosphere, Planet. Space Sci., 23 637-649, 1975.

Peaceman, D. W., and H. H. Rachford, Jr., The numerical solution of parabolic and elliptic differential equations, $J$. Soc. Indust. Appl. Math., 3, 28-41, 1955.

Pirre, M., and C. Delannoy, Evolution de la couche d'ozone et de la température à l'aide d'un modèle bidimensionnel interactif, report, 36 pp., Lab. de Phys. et Chim. de l'Environ., CNRS, Orléans, France, 1989.

Plumb, R. A., Eddy fluxes of conserved quantities by smallamplitude waves, J. Atmos. Sci., 36, 1699-1704, 1979.

Pyle, J. A., and C. F. Rogers, A modified diabatic circulation model for stratospheric tracer transport, Nature, 287, 711$714,1980 a$.

Pyle, J. A., and C. F. Rogers, Stratospheric transport by stationary planetary waves: The importance of chemical processes, Q. J. R. Meteorol. Soc., 106, 421-446, 1980b.

Randel, W. J., Global atmospheric circulation statistics, 1000-1 mb, NCAR Tech. Note TN-295, 245 pp., Natl. Cent. for Atmos. Res., Boulder, Colo., 1987.

Reed, R. J., and K. E. German, A contribution to the problem of stratospheric diffusion by large-scale mixing, Mon. Weather Rev., 99, 313-321, 1965 .

Sasamori, T., J. London, and D. V. Hoyt, Radiation budget of the southern hemisphere, Meteorol. Mag., 13, 9-23, 1972.

Smith, A. K., L. V. Lyjak, and J. C. Gille, The eddy transport of nonconserved trace species derived from satellite data, $J$. Geophys. Res., 93, 11,103-11,122, 1988.

Smolarkiewicz, P. K., A simple positive definite advection scheme with small implicit diffusion, Mon. Weather Rev., 111, 479487,1983

Solomon, S., The mystery of the ozone "hole," Rev. Geophys., $26,131-148,1988$.

Stordal, F., I. S. A. Isaksen, and K. Horntveth, A diabatic circulation two-dimensional model with photochemistry: Simulations of ozone and ground released tracer, J. Geophys. Res., 90, 5757-5776, 1985 .

G. Brasseur and S. Walters, National Center for Atmospheric Research, P.O. Box 3000, Boulder, CO 80307.

M. Dymek and E. Falise, Belgian Institute for Space Aeronomy, 1180 Brussels, Belgium.

M. H. Hitchman, Department of Meteorology, University of Wisconsin, Madison, WI 53706.

M. Pirre, Laboratoire de Physique et Chimie de l'Environnement, 4500 Orléans, France.

(Received March 14, 1989

revised July 31, 1989

accepted September 1, 1989.) 